\title{
Location of studies and evidence of effects of herbivory on Arctic vegetation: a systematic
}

\section{map}

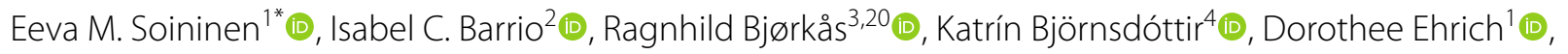
Kelly Hopping ${ }^{5}$ (10, Elina Kaarlejärvi ${ }^{6}$, Anders Lorentzen Kolstad ${ }^{7}$ (D), Svetlana Abdulmanova ${ }^{8}$ (D), Robert G. Björk ${ }^{9,10}$ (D) C. Guillermo Bueno ${ }^{11}$ (D), Isabell Eischeid ${ }^{1,12}$ (D), Rebecca Finger Higgens ${ }^{13}$ (D),

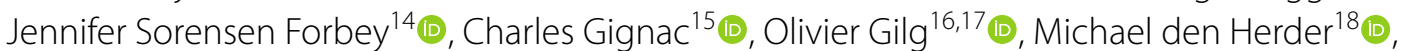
Hildur Søndergaard Holm ${ }^{1}$, Bernice C. Hwang ${ }^{19}{ }^{\infty}$, Jane Uhd Jepsen ${ }^{20}{ }^{(0)}$, Stefaniya Kamenova ${ }^{7,21}$ (D),

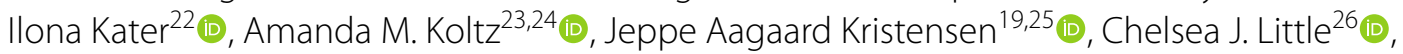

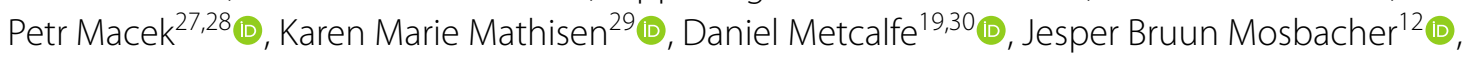
Martin Alfons Mörsdorf ${ }^{31}$ (D) Taejin Park ${ }^{32,33}$ (1) , Jeffrey Propster ${ }^{34,35}$ (D) Aradhana Roberts $^{19}$ (D), Emmanuel Serrano Ferron ${ }^{36}$ (D), Marcus P. Spiegel ${ }^{25}$ (D), Mariana Tamayo ${ }^{37}$ (D), Maria W. Tuomi ${ }^{10}$, Megha Verma ${ }^{38}$,

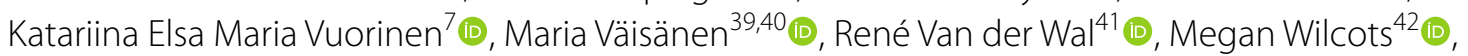
Nigel Yoccoz ${ }^{1}$ (i) and James D. M. Speed ${ }^{7}$ (D)

\begin{abstract}
Background: Herbivores modify the structure and function of tundra ecosystems. Understanding their impacts is necessary to assess the responses of these ecosystems to ongoing environmental changes. However, the effects of herbivores on plants and ecosystem structure and function vary across the Arctic. Strong spatial variation in herbivore effects implies that the results of individual studies on herbivory depend on local conditions, i.e., their ecological context. An important first step in assessing whether generalizable conclusions can be produced is to identify the existing studies and assess how well they cover the underlying environmental conditions across the Arctic. This systematic map aims to identify the ecological contexts in which herbivore impacts on vegetation have been studied in the Arctic. Specifically, the primary question of the systematic map was: "What evidence exists on the effects of herbivores on Arctic vegetation?".

Methods: We used a published systematic map protocol to identify studies addressing the effects of herbivores on Arctic vegetation. We conducted searches for relevant literature in online databases, search engines and specialist websites. Literature was screened to identify eligible studies, defined as reporting primary data on herbivore impacts on Arctic plants and plant communities. We extracted information on variables that describe the ecological context of the studies, from the studies themselves and from geospatial data. We synthesized the findings narratively and created a Shiny App where the coded data are searchable and variables can be visually explored.
\end{abstract}

\section{*Correspondence: eeva.soininen@uit.no of Norway, 9037 Tromsø, Norway

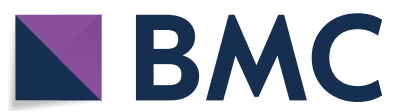

${ }^{1}$ Department of Arctic and Marine Biology, UiT-The Arctic University

Full list of author information is available at the end of the article
(C) The Author(s) 2021, corrected publication 2022. Open Access This article is licensed under a Creative Commons Attribution 4.0 International License, which permits use, sharing, adaptation, distribution and reproduction in any medium or format, as long as you give appropriate credit to the original author(s) and the source, provide a link to the Creative Commons licence, and indicate if changes were made. The images or other third party material in this article are included in the article's Creative Commons licence, unless indicated otherwise in a credit line to the material. If material is not included in the article's Creative Commons licence and your intended use is not permitted by statutory regulation or exceeds the permitted use, you will need to obtain permission directly from the copyright holder. To view a copy of this licence, visit http://creativecommons.org/licenses/by/4.0/. The Creative Commons Public Domain Dedication waiver (http://creativecommons.org/publicdomain/zero/1.0/) applies to the data made available in this article, unless otherwise stated in a credit line to the data. 
Review findings: We identified 309 relevant articles with 662 studies (representing different ecological contexts or datasets within the same article). These studies addressed vertebrate herbivory seven times more often than invertebrate herbivory. Geographically, the largest cluster of studies was in Northern Fennoscandia. Warmer and wetter parts of the Arctic had the largest representation, as did coastal areas and areas where the increase in temperature has been moderate. In contrast, studies spanned the full range of ecological context variables describing Arctic vertebrate herbivore diversity and human population density and impact.

Conclusions: The current evidence base might not be sufficient to understand the effects of herbivores on Arctic vegetation throughout the region, as we identified clear biases in the distribution of herbivore studies in the Arctic and a limited evidence base on invertebrate herbivory. In particular, the overrepresentation of studies in areas with moderate increases in temperature prevents robust generalizations about the effects of herbivores under different climatic scenarios.

Keywords: Browsing, Grazing, Grubbing, Defoliation, Tundra, Invertebrate, Vertebrate, Forest-tundra, Plant-herbivore interaction

\section{Background}

Herbivores are a central component of northern socioecological systems, both as subsistence resources and due to their influence on ecosystem structure and function [1, 2]. For example, many northern communities rely on vertebrate herbivores to support local economies through hunting (e.g., geese, ptarmigan, caribou) or herding (e.g., reindeer) $[3,4]$. Similarly, outbreaks of invertebrate herbivores can influence the livelihood of northern communities [5] through their dramatic impacts on vegetation and the subsequent cascading effects on local wildlife $[6,7]$. Herbivores also play an important ecological role in Arctic tundra ecosystems by influencing soils [8] and plant communities $[9,10]$, with consequences for ecosystem processes [11]. Moreover, herbivores have the potential to offset some of the effects of ongoing warming in tundra ecosystems by counteracting increases in deciduous shrub cover $[12,13]$ or advances of the treeline [14]. Thus, understanding how herbivory influences the responses of Arctic ecosystems to environmental change can help guide appropriate adaptive strategies to sustain ecosystem functioning and the provision of ecosystem services [1].

However, the effects of herbivores on plants and ecosystem functioning are far from homogeneous across the Arctic. Rather, herbivore effects depend on the local conditions, i.e., ecological context $[15,16]$. We here define ecological context as the range of physical and biological conditions that can affect the interplay between plants and herbivores, and include descriptions of geography, climate, food web composition and structure and human use. For example, plant responses to herbivory have been shown to depend on local productivity $[10,17]$ and temperature [12]. The effects of herbivores on plants are thus expected to differ along climatic gradients within the Arctic [18]. Distance to the coast can matter due to marine subsidies to the food web [19] or salinity [20,21] and distance to the treeline due to spillover of boreal herbivores [22-24]. The magnitude of recent warming and the composition of herbivore communities are also important $[25,26]$. The extent to which the literature on Arctic herbivory covers the range of possible ecological contexts will determine which conclusions can be drawn about the role of herbivores in shaping Arctic vegetation. While uneven geographical cover of the Arctic has been identified for environmental studies more generally [27], we lack a systematic overview of which ecological contexts are covered by the existing literature on herbivore impacts.

To better understand the present "state of affairs" of Arctic herbivory research, we systematically mapped the coverage of ecological context in studies considering the effects of herbivores on vegetation. Individual studies that address the effects of herbivores on tundra ecosystems are often conducted at a specific location and within a specific ecological context. Although these studies are designed in ways that are adapted to their local context, they can also be considered as sample points within the larger, discipline-wide study of the effects of herbivores within the circumpolar Arctic. A first attempt to assess whether generalizable conclusions can be produced from these studies includes gathering information about the number of studies and assessing how well they cover the underlying ecological gradients across the Arctic. Uneven distribution of studies across a particular ecological gradient indicates that enough evidence may be available for some parts of the gradient but not for others. In such case conclusions on the effects of herbivores cannot be generalized across the Arctic. This systematic map will thus assess our ability to make generalizable and robust conclusions on Arctic herbivory. Furthermore, identifying areas that are underrepresented in the current evidence base will facilitate targeted research efforts to fill these gaps. 
The topic for this systematic map was originally identified at a specialist workshop aimed at identifying data gaps in herbivory research, where the main stakeholder group of scientists working on Arctic herbivory was invited to participate. A core team developed the protocol that is used in this systematic map [28]. Active participation in the systematic map and co-authorship was encouraged through an open call for collaboration through the Herbivory Network (https://herbivory.lbhi. is/), which currently features more than 200 members and includes relevant stakeholders for the topic of this systematic map.

\section{Objective of the review}

We used a published protocol to map the coverage of ecological contexts in which herbivory has been studied in the Arctic [28]. Hence, the primary question of the systematic map was "What evidence exists on the effects of herbivores on Arctic vegetation?" and it covers terrestrial Arctic plants and plant communities (population) responses (outcome) to herbivory (exposure). Note that we did not assess the strength of the herbivore impacts on vegetation but focused on the coverage of the existing studies across the underlying environmental conditions across the Arctic. In addition to vertebrate and invertebrate herbivores' direct effects on plants through consumption, exposure also included their disturbance and fertilization effects. Studies also had to compare a certain level of herbivory to no herbivory or alternative levels of herbivory (comparator), such as experimental exclusion or herbivore abundance changes across space or time. Thus, the primary question of the systematic map contains four key elements, needed for the question to be answerable: the population of interest (terrestrial Arctic plants and plant communities), the exposure (herbivory); the comparator (different levels of herbivory) and the outcome (any response from the population to the exposure). This PECO-type question defines the eligibility criteria for individual studies, as outlined below.

\section{Methods}

This systematic map follows methods described in a protocol by Soininen et al. [28] to map the existing evidence on the effects of herbivory on Arctic vegetation. Throughout this map, we use the following terminology: an article refers to any publication/document matching our search criteria (below), and a study is a report of herbivory effects using a certain study design in a given ecological context. An article could thus contain from one to several studies. The systematic map conforms to ROSES reporting standards (see Additional file 1).

\section{Deviations from the protocol}

Some minor deviations from the original protocol were necessary when developing the systematic map and are described in the sections below. These deviations included (i) the use of other maps for delimiting the study region as the original one was not available and (ii) limiting the check of redundant studies to those that were conducted in the same location. The latter was deemed sufficient as only studies from a shared location could be redundant. In addition, (iii) assessing repeatability of the data coding strategy at the full-text stage by replicate extraction of data from at least $10 \%$ of the studies was deemed unnecessary as all coded data were checked for consistency by two reviewers.

\section{Search for articles}

We searched for relevant literature first from the global databases of Web of Science Core Collection (all years search within Topic) and Scopus (article title, abstract and keyword search with no further limitations applied). Thereafter, we searched literature that these databases might have missed, and grey literature, from Google Scholar (title search standardized to disregard search history, including only the first 300 search results) and local/ regional and specialist databases or sources (listed in Additional file 2).

The search string for the systematic map was optimized during scoping exercises as described by Soininen et al. [28] and comprised two substrings: one targeted at delimiting the study region and system, and the other targeted at the exposure component of our primary question (i.e., herbivory). The full search string (formatted for Web of Science) was:

(arctic OR subarctic OR tundra) AND (herbivor* OR graz* OR browser OR browsing OR grubb* OR trampl* OR defolia* OR ((invertebrate OR insect) AND (gall* OR mining OR miner)))

The specificity of the search string, that is the proportion of relevant studies returned by the search, was relatively low, with $46 \%$ of the documents excluded at title screening stage in the current search (Fig. 1). Still, the specificity of the search string was deemed adequate, as it was not possible to include additional search terms to narrow down the population of interest [28]. The sensitivity of the search string, that is its ability to find all relevant studies was assessed by comparing the results obtained with the full search and the two substrings separately, to identify potentially relevant documents that could have been missed. The sensitivity of the search string was very high, with only one article out of a subset of 1000 articles deemed as potentially relevant [28]. 


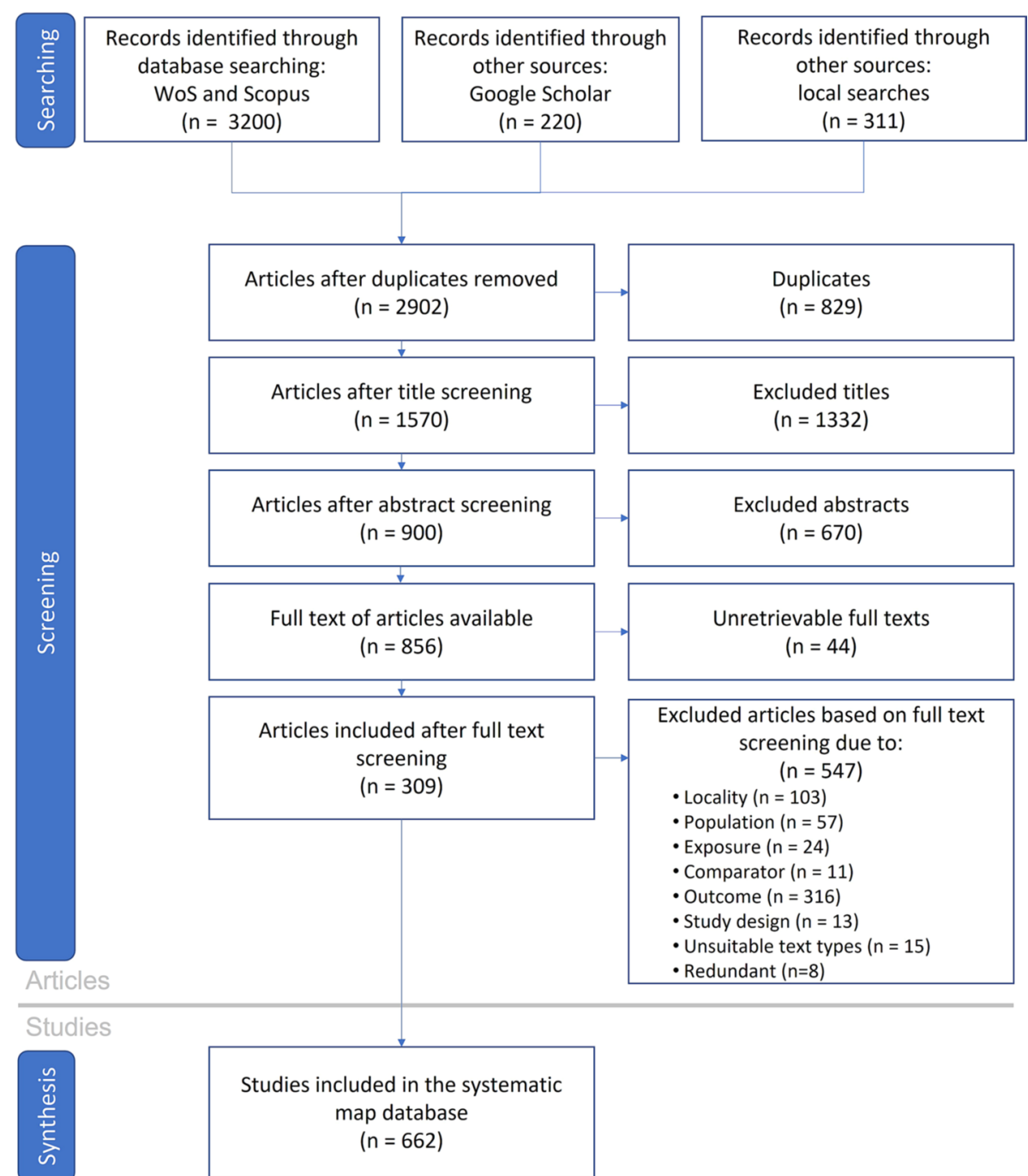

Fig. 1 RepOrting standards for Systematic Evidence Syntheses (ROSES) diagram indicating the inclusion and exclusion process, including the number of studies retained at each stage of the process. At the full text stage, studies were excluded if they were located outside the study region (locality), if they did not target Arctic terrestrial vegetation (population), did not assess effects of herbivores on plants (exposure), did not compare different levels of herbivory (comparator), focused on ecosystem components other than plants (outcome), their design did not address current ecological contexts in the Arctic (study design), represented unsuitable text types or presented the same data as other studies (redundant). The ROSES diagram is based on [97]

We conducted our search in English in global search sources, and English together with relevant local languages (Russian, French, Finnish, Swedish, Norwegian, Icelandic and Danish) in searches from local/regional sources. In some cases, the full search strings had to be simplified because some search engines did not allow Boolean operators or the use of "wildcards" (*) or could handle only a reduced number of terms. Full details on the search sources and strings used in each search engine and how they were implemented in other languages, as well as access information on institutional access to paywalled databases are provided in Additional file 2.

\section{Article screening and study eligibility criteria Screening process}

Screening of the articles for relevancy was structured in four stages: (i) title screening, (ii) abstract screening, (iii) locality screening, and (iv) screening during data coding from the full text. Each article was assessed by two reviewers at the title and abstract screening stages, except for those found through Google Scholar and local/regional databases that were assessed by one reviewer. Locality and full text screening were assessed by one reviewer, with additional reviewers in cases that were not clear. These numbers refer to reviewers per 
article; several reviewers were involved in each screening phase.

During screening, we erred on the side of inclusion. Exclusion of an article at title and abstract screening stages occurred upon the agreement of two independent reviewers. The reviewers first noted whether an article should be excluded based on the title. If not, they screened the abstract and noted either "excluded based on abstract" or "included". In the case of reviewer disagreement about inclusion, the article was kept for further stages of screening. No reviewers assessed articles they had authored or co-authored. When one reviewer had scored an article to be excluded based on title and the other reviewer based on abstract, the article was assigned the score "exclude based on abstract". Additional articles that were found through Google Scholar or from local/ regional sources were screened for both title and abstract by one reviewer and were only included in our database if they passed this screening stage.

Articles that passed the title and abstract screening stage were then assessed for their geographical locality by one reviewer. Locality screening was based on geographical coordinates that were given in the text, extracted from maps provided in the publication, or extracted from Google Maps based on study location names mentioned in the text. To delimit the study region, we used the southern limit of the Subarctic as defined by the Conservation of Arctic Flora and Fauna (CAFF, [29]). This region contains tundra, the tundra-forest ecotone and boreal forests. To limit the scope to tundra and tundra-forest ecotone, we excluded areas south of the Subarctic zone, based on the definition used in the Arctic Biodiversity Assessment [30] and excluded studies in boreal forests based on full text screening.

When extracting locality coordinates, the reviewer also did a first screening of the full text to identify any obvious reasons for exclusion, such as being a review paper with no primary data. Articles that passed the locality screening were thereafter read in full and their content judged by at least one reviewer. The full text screening stage was in practice combined with the data coding. Reviewers carefully checked the full text against the eligibility criteria and reasons for exclusion were recorded. When in doubt, the article was reviewed by an additional reviewer. The complete database of retrieved articles, with information on exclusion stage and reasons (for full text stage only) is provided in Additional file 3 (see also Fig. 1). Locality screening diverges from the description in the published protocol [28], where the CAFF vegetation zone map ("CAFF Map Nr. 10", [31]) was planned to be used to delimit the Arctic region. That map was however no longer available, leading us to use the approach described here.
We assessed the repeatability of title and abstract screening by measuring the consistency among reviewers to either include or exclude an article. For this, we used percent agreement and Cohen's kappa ( $\mathrm{K}$ ) statistic [32]. Percent agreement is calculated as the number of agreements divided by the total number of screened articles, and kappa is a ratio of the relative observed agreement to the probability of random allocation. Consistency among two reviewers to exclude an article based on title screening alone was low $(49.3 \%, \kappa=0.54$ indicating 'weak agreement' according to McHugh [33], N=2704). After abstract screening, consistency of scoring was considerably higher: two independent reviewers agreed to exclude an article in $74.1 \%$ of cases, include an article in $13.4 \%$ of cases and disagreed only in $12.5 \%$ of cases $(\kappa=0.61$, 'moderate agreement' [33], $\mathrm{N}=2704$ ). The majority $(79.6 \%)$ of articles where reviewers disagreed after the title and abstract screening stage were excluded based on their locality or full-text evaluation. One of the main reasons for exclusion at the full-text stage was the lack of an eligible outcome.

Assessing the repeatability of the location screening stage was deemed not necessary, as coordinates were extracted from the study (either from the text, figures, maps or inferred from site names) and checked against the study area using maps. Full text screening was combined with data coding and conducted by a single reviewer, except in unclear cases where the opinion of additional reviewers was sought. Reasons for exclusion at full text screening are listed in Additional file 3. The consistency of this stage was ensured by checking all coded data by two reviewers (see below). In addition, 45 articles excluded at full text stage (corresponding to $10 \%$ of articles excluded at this stage for other reasons than location) were independently assessed by a second reviewer. Consistency among the two reviewers to exclude an article based on full text was high; all but one of the articles were unanimously excluded. For the last article, the second reviewer sought for the opinion of an additional reviewer, whereafter also this article was deemed to be excluded.

\section{Eligibility criteria}

Eligible studies were defined as those as reporting primary data on herbivore impacts on Arctic plants and plant communities. To be included, studies had to include an eligible population, exposure, comparator and outcome (as defined in the objective of the review above). In addition, studies had to fulfill some requirements regarding their study design as described in this section. 
Eligible population Studies had to target an eligible population, i.e., studies were excluded if they did not study Arctic terrestrial vegetation. This filtering included additional locality information, such as describing the study sites as boreal forests or temperate grasslands and, in some cases, inspecting Google Earth images of the study location to assess the extent of canopy cover and proximity to open tundra. Studies were also excluded on the grounds of not targeting an eligible population if the ecological context did not correspond to any current climatic context of the Arctic, such as palaeoecological studies or greenhouse studies not mimicking Arctic growing conditions.

Eligible exposure Studies had to target an eligible exposure to herbivores, that is, they had to assess the effects of herbivores on plants (consumptive effects, fertilizing, trampling and other types of disturbance). To be included, studies mimicking effects that could be related to herbivore activities needed to explicitly state their link to herbivory.

Eligible comparator Furthermore, studies had to assess the effect of herbivores by comparing a given level of herbivory or other herbivore-related effects to either no herbivory or another level(s) of herbivory; that is, studies needed to have an eligible comparator. The type of comparison was not restricted, and thus different types (e.g., factor levels of experimental treatments, continuous variable changing across spatial or temporal gradients) and intensities of the comparison (e.g., number of herbivory levels, magnitude of the difference in herbivory along a gradient) were eligible. We included studies that measured herbivore presence in direct and indirect ways such as biting marks or galls but excluded those that did not relate herbivore presence to any measurable effect of herbivores on plants.

Eligible outcome We excluded studies lacking an eligible outcome if they assessed the effects of herbivory on ecosystem components other than plants or plant communities. We included lichens but excluded soil properties and plant symbionts such as microbial endophytes or mycorrhizal fungi. Studies were also excluded on the grounds of lacking an eligible outcome when they presented no quantitatively analyzable primary data, as in the case of many reviews, book chapters, synthesis papers, or perspectives.

Eligible types of study design Studies had to address herbivore effects on plants in a given ecological context within the Arctic; thus, some modeling studies were excluded based on their lack of an eligible study design.
Additional criteria We excluded studies for which we could not access electronic or paper copies of the full text, as this prevented assigning studies to an ecological context. Similarly, we excluded studies that were not in a suitable format (Fig. 1), such as corrections of published articles, maps and raw datasets (cf. "Unsuitable text types" in ref. [34]). We further excluded studies that presented data already reported in another article. For chapters of academic theses that were published as separate studies, we only included the published peer-reviewed versions, and for annual reports that presented incremental data, we only included the longest time-series. For all other studies, we checked for potential redundancy based on the study site. We first edited the spelling of study sites to be consistent across studies and then cross-checked all studies conducted at a given study site. We coded a study as redundant if it presented a temporal or spatial subset of data that was also included in another article. In cases of data duplication, we included the most recent study.

\section{Study validity assessment}

Because the primary aim of the systematic map was to identify the ecological contexts where herbivory has been studied, critical appraisal of the validity of the studies based on aspects such as replication, confounding factors, or issues with interpretation of measured variables is not of paramount importance (but see examples of systematic reviews on herbivores where such appraisal has been done $[18,35])$. Thus, we did not exclude any study based on such criteria but included an appraisal of (i) the spatio-temporal extent and resolution of the study designs, and (ii) lack of information on study design. This information was extracted from the studies as part of the data coding (Table 1), and allowed us to explore whether local (i.e., study area size less than $10 \times 10 \mathrm{~km}$ ) or shortterm (i.e., 1-year) studies were more common for some of the ecological contexts or herbivore groups than others. The definitions of these spatial and temporal groupings were, as described in the protocol [28], based on exploring the ranges of these variables in the studies retrieved by our search.

\section{Data coding strategy}

For each study that passed all the screening stages, we extracted information on variables reporting the study design and study method, the target population (plant), exposure (type of herbivore) and comparator (how the contrasting levels of herbivory were obtained) and variables describing the ecological context (Table 1). Additional information for these variables, such as potential values, examples and specifications, and other variables extracted from the studies but not presented in detail in this paper are given in Additional file 4. 
Table 1 Ecological context variables extracted from the studies included in the systematic map database during data coding

\begin{tabular}{|c|c|c|c|}
\hline Ecological context group & Variable & Variable description & Source (reference) \\
\hline \multirow[t]{7}{*}{ Geographic space } & Elevation $^{\mathrm{b}}$ & Elevation (meters above sea level) & $P, D[91]$ \\
\hline & Distance_to_treeline & $\begin{array}{l}\text { Distance }(\mathrm{km}) \text { to the southern border of Arctic } \\
\text { subzone E. Negative numbers correspond to } \\
\text { locations to the south of this border }\end{array}$ & $D$ [92] \\
\hline & Distance_from_coast & Distance from the coast $(\mathrm{km})$ & D [coastline used to create 92] \\
\hline & Bioclimatic_zone & $\begin{array}{l}\text { Bioclimatic zone } \mathrm{A} \text { to } \mathrm{E} \text {, or outside the Arctic, } \\
\text { as defined by the bioclimatic zonation }\end{array}$ & $D$ [92] \\
\hline & Soil_type ${ }^{b}$ & $\begin{array}{l}\text { Soil type class, according to the Digital Soil } \\
\text { Map of the World }\end{array}$ & $\mathrm{D}[39]$ \\
\hline & Permafrost & $\begin{array}{l}\text { Presence and type of permafrost: continuous, } \\
\text { discontinuous, sporadic, isolated patches }\end{array}$ & $\mathrm{D}[38]$ \\
\hline & Disturbance & $\begin{array}{l}\text { Disturbance that occurs in the study system } \\
\text { and could impact the results and is discussed } \\
\text { by the authors, e.g., fire, flooding, ice/winter } \\
\text { damage, pollution }\end{array}$ & C \\
\hline \multirow[t]{7}{*}{ Climate space } & Mean_annual_temperature ${ }^{c}$ & BIO1 extracted from WorldClim & $\mathrm{P}, \mathrm{D}[93]$ \\
\hline & Max_temperature_of_warmest_month ${ }^{c}$ & $\mathrm{BlO5}$ extracted from WorldClim & $\mathrm{D}[93]$ \\
\hline & Temperature_annual_range ${ }^{c}$ & $\mathrm{BlO7}$ extracted from WorldClim & $D[93]$ \\
\hline & Temperature_seasonality ${ }^{c}$ & $\mathrm{BlO} 4$ extracted from WorldClim & $\mathrm{D}[93]$ \\
\hline & Mean_annual_precipitation ${ }^{c}$ & $\mathrm{BIO12}$ extracted from WorldClim & P, D [93] \\
\hline & Growing_season_length & $\begin{array}{l}\text { Duration of growing season (days, mean dur- } \\
\text { ing 1982-2014) }\end{array}$ & $D[94]$ \\
\hline & Vegetation_greenness & $\begin{array}{l}\text { Cumulative daily growing season NDVI, mean } \\
\text { during 1982-2014 }\end{array}$ & $D[94]$ \\
\hline \multirow[t]{3}{*}{ Climate change space } & Extent_of_recent_warming & $\begin{array}{l}\text { Change in mean temperature from period } \\
1951-1980 \text { to period } 2000-2020\left({ }^{\circ} \mathrm{C}\right)\end{array}$ & $\mathrm{D}[95,96]$ \\
\hline & Extent_of_recent_greening & $\begin{array}{l}\text { Extent of last decades (1982-2014) change in } \\
\text { cumulative daily growing season NDVI (\% per } \\
\text { decade) }\end{array}$ & $D[94]$ \\
\hline & Extent_of_recent_growing_season_change & $\begin{array}{l}\text { Extent of last decades (1982-2014) change in } \\
\text { growing season length (days per decade) }\end{array}$ & $\mathrm{D}[94]$ \\
\hline \multirow[t]{5}{*}{ Food web space } & Herbivore_species_richness & Species richness of vertebrate herbivores & $D[37]$ \\
\hline & Herbivore_functional_diversity & Functional diversity of vertebrate herbivores & $D[37]$ \\
\hline & Herbivore_phylogenetic_diversity ${ }^{a}$ & Phylogenetic diversity of vertebrate herbivores & $\mathrm{D}[37]$ \\
\hline & Food_web_context_other_herbivores & $\begin{array}{l}\text { Is the presence of other herbivores in the study } \\
\text { area described? }\end{array}$ & C \\
\hline & Food_web_context_predators & $\begin{array}{l}\text { Is the presence of predators in the study area } \\
\text { described? }\end{array}$ & C \\
\hline \multirow[t]{5}{*}{ Human space } & Human_density ${ }^{a}$ & Human population density (per km², in 2015) & $D[40]$ \\
\hline & Human_footprint ${ }^{\mathrm{a}}$ & $\begin{array}{l}\text { Cumulative human pressure on the environ- } \\
\text { ment in 2009, }\left(\text { per } \mathrm{km}^{2}\right) \text {. Combines measures } \\
\text { of built-up environments, population density, } \\
\text { electric power infrastructure, crop lands, pasture } \\
\text { lands, roads, railways, and navigable waterways }\end{array}$ & $\mathrm{D}[41,42]$ \\
\hline & Management_study_area & $\begin{array}{l}\text { Management status of the study area, e.g., } \\
\text { historical, current }\end{array}$ & C \\
\hline & Conservation_study_area & $\begin{array}{l}\text { Conservation status of the study area, e.g., } \\
\text { protected area, common habitat }\end{array}$ & C \\
\hline & Conservation_focus & $\begin{array}{l}\text { Is the study framed within a conservation } \\
\text { context (i.e., conservation aims are mentioned } \\
\text { or not)? }\end{array}$ & C \\
\hline
\end{tabular}

Values in column "source" describe where the data is extracted from: P for publication (i.e., data explicitly available in the published document), D for digital spatial data layers (i.e., data extracted from a data layer based on the spatial coordinates given in the publication), and C for classified by the reviewers based on information available in the publication. For variables denoted with $\mathrm{P}$ and $\mathrm{D}$, we used the D-version in our analysis to reduce the heterogeneity in the accuracy reported across studies. See Additional file 4 for a full list of variables extracted from the studies

${ }^{\text {a }}$ Variable added after publication of the protocol

${ }^{b}$ Variable data source differs from the planned source (i.e., from the reference given in protocol)

${ }^{c}$ Note that all 19 WorldClim variables were extracted and explored, but here we list only the variables for which results are presented in the text. The variables differ from the protocol, where use of three main PCA axis of variation across these variables was outlined 
The values for the ecological context variables were recorded as they were reported in the study, either with data explicitly available in the publication (variables indicated with $\mathrm{P}$ in Table 1), classified by the reviewers based on information available in the publication $(\mathrm{C}$ in Table 1) or extracted from a data layer based on the spatial coordinates given in the publication ( $\mathrm{D}$ in Table 1 ). We did not attempt to contact the authors of the studies to obtain missing information or confirm unclear points, as this could have biased the quality of information extracted from studies where corresponding authors were no longer available.

One article could contain information about several studies when it included more than one study question, methodological approach or ecological context. For instance, when an article presented different datasets of plant-herbivore pairs, such as one experimental and one observational dataset, these were considered as separate studies. Similarly, when an article presented data from several locations for which ecological contexts were described separately, datasets from the different locations were considered as separate studies. In cases where an article contained more than one study, information about the variables was recorded for each study.

After all the data were coded, two reviewers (EMS, ICB) edited possible dissimilarities in spelling, checked accuracy and corrected obvious errors (such as deviations from pre-defined factor levels), and identified additional uncertainties in the inclusion of studies. At this stage, lengthy descriptions for some variable values were summarized into more general categories. For example, when detailed descriptions of the habitats were provided in the text, they were replaced by a shorter, more general description. In the original protocol [28] it was stated that data from at least $10 \%$ of the studies would be extracted by at least two reviewers to reduce discrepancies and inconsistencies between reviewers. Since all coding data were checked for consistency by two reviewers, this step was considered unnecessary.

\section{Data mapping method}

To code data from the full text of each study, we used the Excel spreadsheet published as an appendix of the systematic map protocol [28]. The data were collated using R-scripts (available on GitHub https://github.com/James DMSpeed/ArcticHerbivorySystematicMap). We then extracted geospatial ecological context variables (Table 1) and added them to the dataset.

We grouped the ecological context variables according to whether they described the geography, climate, climate change, food web, or human use (see Table 1 for variables, their definitions, and how they were extracted).
We used univariate and pairwise plots to visually explore the available ecological space within the Arctic (i.e., the range of values of the variables that are represented in the study region) and to assess how much of that space is covered by the available studies. We delimited the Arctic study region by coastline but did not remove other areas such as glaciers or lakes. In our narrative synthesis of the results, we highlight biases in the available studies across the ecological contexts, as they point to areas for which abundant information exists and where more studies are needed.

The raw data are available for download (Additional file 5), as well as through a Shiny App: https://shiny.vm. ntnu.no/users/speed/ArcticHerbivorySystematicMap/, created with the R-package "Shiny" [36]. The Shiny App helps the reader navigate the database and visualize the contribution of individual studies. The app allows plotting studies on a geographic map, filtering studies based on different criteria (e.g., selecting country, species, study language, herbivore type, and different aspects of the study design) and interactive exploration of the variables using bar plots, histograms and pairwise plots. This allows the reader to explore the data freely, including variables that are not the focus of the narrative synthesis of results in this study. The pairwise plots allow simultaneous visualization of study design variables together with two ecological context variables to identify which contexts have been studied using different approaches.

\section{Review findings}

\section{Review descriptive statistics}

The literature search underpinning this review was conducted on 13th February 2019 (Web of Science and Scopus, refer to Additional file 2 for dates in local searches). We identified 3200 articles from searches in Web of Science and Scopus, an additional 311 from local/regional and specialist databases/sources as well as an additional 75 from Google Scholar (Fig. 1; Additional file 3). After evaluation of eligibility across all screening stages, the final evidence base included 309 articles, split into 662 studies. The full list of included articles can be found in Additional file 3, and the full list of studies is presented in the Shiny App.

\section{Mapping the quantity of studies relevant to the questions Approaches, study designs, and methods}

Experimental and observational field studies were equally common ( $\mathrm{n}=299$ and 306 studies, respectively, for definitions see Additional file 4). In addition to field studies, the evidence base included remote sensing studies $(\mathrm{n}=28)$, modeling studies $(\mathrm{n}=19)$ and greenhouse studies $(n=12)$. Most of the experimental field studies had 

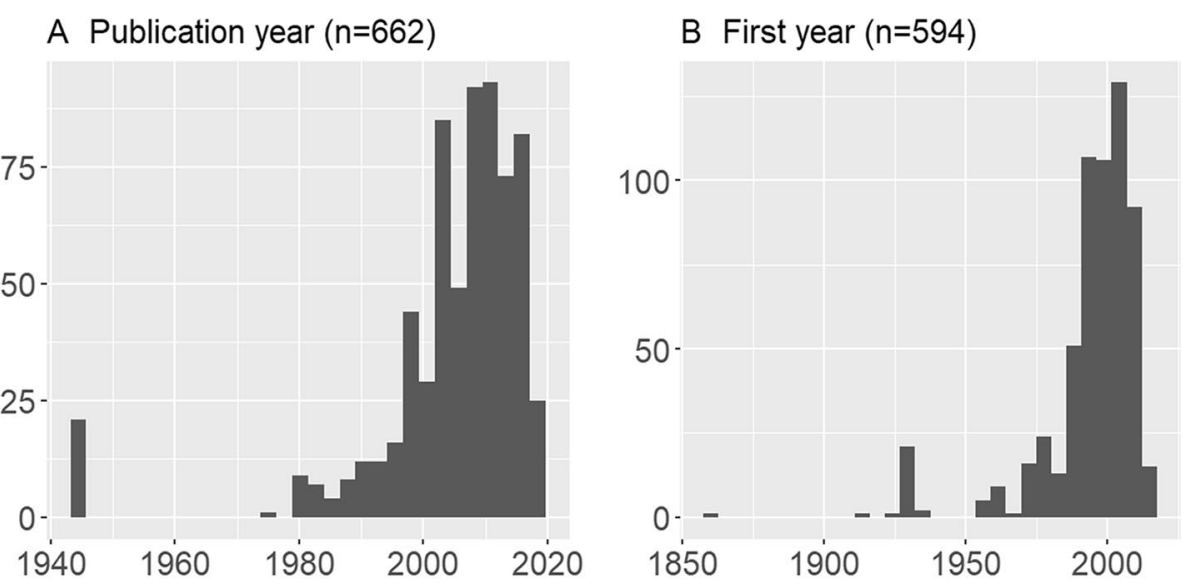

C Temporal extent $(n=615)$
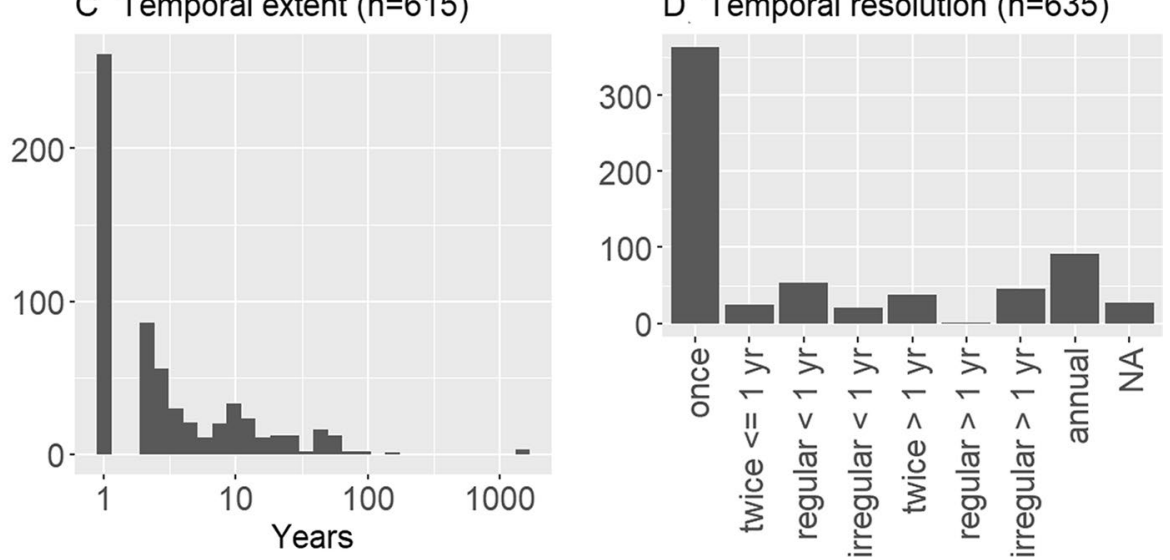

Fig. 2 The distribution of studies across time and temporal study design. All y-axes show a count of studies. $\mathbf{A}$ shows study publication year and B the first year when both plant and herbivore elements were measured. $\mathbf{C}$ shows the temporal extent of the studies, defined as the number of years when both plant and herbivore elements were measured. Note that the studies with temporal extent longer than 1000 years come from one modeling study. D shows the temporal resolution of the studies, defined as the interval between measurements of the outcome (plant), if regularly measured or not and for how long. Sample size refers to studies for which the variable was feasible to assign

no additional exposures other than herbivory, but among those studies that had additional experimental treatments, warming ( $\mathrm{n}=26$ studies) and nutrient manipulation ( $\mathrm{n}=23$ studies) were the most common.

Most studies were published after 1980, with a stark rise in studies occurring around 2000 and peaking around 2010 (Fig. 2A, B). The majority of studies reported on data collected only once $(n=363)$ and/or during only one year $(n=262)$, although data sampling of 112 studies spanned more than a decade (Fig. 2CD). The results were most often reported at finegrained spatial resolution $(\mathrm{n}=253$ up to $1 \times 1 \mathrm{~m}$ plots and $\mathrm{n}=123$ from $1 \times 1 \mathrm{~m}$ to $10 \times 10 \mathrm{~m}$ plots). The study area size was most often small $(\mathrm{n}=170$ at $1 \times 1 \mathrm{~km}$ or less, $\mathrm{n}=121$ between $1 \times 1 \mathrm{~km}$ and $10 \times 10 \mathrm{~km}$, and $\mathrm{n}=65$ between $10 \times 10 \mathrm{~km}$ and $100 \times 100 \mathrm{~km}$ ). Note that we defined the study area size as a square based on the study area description and coordinates, but many studies provided so little information that we were not able to assign them to a study area category $(n=156)$.

\section{Arctic plants and plant communities (population)}

To gain an overview of the studied plant types, we grouped the plant species and groups reported by the studies into plant functional groups (for definitions, see Additional file 6). Graminoids were the most commonly studied plants, with 343 studies including data on this functional group. They were followed by deciduous dwarf shrubs $(n=283)$, forbs $(n=235)$, evergreen dwarf shrubs $(n=224)$, bryophytes $(n=214)$, lichens $(n=174)$, deciduous trees $(n=114)$, the vascular plant community as a whole $(\mathrm{n}=94)$, deciduous tall shrubs $(\mathrm{n}=88)$, ferns and allies $(n=61)$, evergreen trees $(n=9)$ and evergreen tall shrubs $(\mathrm{n}=4)$ (Fig. 3A). Note that deciduous and evergreen trees are included here, as the study region also included the tundra-forest ecotone. 
Often, plant response to herbivory was measured at one level of biological organization but results were reported at a more aggregated level. For example, some studies conducted measurements on individual plants but reported their results for the plant population/species (for instance recording survival of marked plant individuals and reporting survival rate per species per treatment). Thus, measurements most often targeted plant data at the population/species level ( $n=320$ studies), followed by individual $(\mathrm{n}=198)$, plant functional or taxonomic group $(n=93)$ and plant community $(n=84)$ levels. In contrast, results were reported at the population/species $(n=315)$, plant functional or taxonomic group $(n=192)$, plant community $(n=178)$ and individual $(n=63)$ levels (Fig. 3B).

\section{Herbivores (exposure)}

The vast majority of studies focused on vertebrate herbivores $(n=582)$ compared to invertebrates $(n=75)$ (Fig. 3). We divided vertebrate herbivore species into functional groups according to Speed et al. 2019 [37]. This classification is based on a suite of functional traits reflecting the ecology of the herbivore species and recognizes three functional groups: (i) waterfowl (limnic-habitat associated species migrating outside the Arctic for winter exemplified by snow goose Anser caerulescens), (ii) small rodents and pikas (hindgut-fermenter, burrowing species exemplified by Norwegian lemming Lemmus lemmus), and (iii) other vertebrates (larger-bodied, facultative-generalist species exemplified by reindeer Rangifer tarandus). The functional group "other vertebrates" was most studied (385 studies), and studies of this group were by far dominated by Rangifer tarandus, which alone was the focus of 333 studies (Fig. 3). The group "small rodents and pikas" was studied in 153 studies. These studies were dominated by genera Lemmus and Myodes (81 and 73 studies, respectively). The group "waterfowl” was studied in 128 studies, of which almost half targeted the genus Branta ( $\mathrm{n}=60)$ (Fig. 3).

Among invertebrate herbivores, we separated functional groups based on feeding mode: defoliating invertebrates were addressed in 67 studies (mainly Operophtera brumata, $\mathrm{n}=32$, and Epirrita autumnata, $\mathrm{n}=18$ ), while other types of invertebrate herbivores were very rarely studied ( $n=3$ studies for galling invertebrates, one for phloem feeders, 2 for root-feeding invertebrates and 2 for invertebrates feeding on reproductive structures).

While studies targeting the effects of invertebrate herbivores were mostly observational, there was a balanced mix of experimental and observational approaches for studies on vertebrate herbivores (Fig. 3C). Studies targeting multiple herbivores $(n=90)$ used experimental approaches more often than observational ones $(n=71$ experimental and 19 observational).

Most studies assessing the effects of invertebrate herbivores reported their outcomes at the plant individual or population/species levels, while those assessing the effects of vertebrates reported their outcomes mainly at higher biological organization levels, including plant population/species, groups of species and communities (Fig. 3B).

\section{Comparison between levels of herbivore impact (comparator)}

Field studies included a variety of approaches to assess the impacts of herbivory. The most frequent approach in experimental studies was the use of exclosures that eliminated a certain type of herbivory $(n=169$ studies), followed by simulated herbivory $(n=83)$ and to a lesser extent the use of fences with different herbivory levels on either side $(n=34)$ or enclosures $(n=22)$. In observational field studies, spatial contrasts in herbivory ( $\mathrm{n}=176$ studies including spatial gradients), fences $(n=46)$, and herbivore outbreaks $(n=41)$ were the most common approaches. Temporal contrast in herbivory was also used, but only 18 studies had increasing or decreasing herbivore populations as their main means to compare herbivore intensities. Control-impact or beforeafter-control-impact designs were used in 420 studies, representing $99 \%$ of field experiments and $36 \%$ of observational field studies.

\section{Response types to herbivory (outcome)}

Almost half of the studies $(n=317)$ measured more than one type of outcome following exposure to herbivory. Overall, plant biomass was the most common response type $(n=247)$, followed by morphological measures ( $\mathrm{n}=188$, including for example canopy height or leaf demography), vegetation cover $(n=157$, including the cover of plant species or groups), measures of plant community diversity $(n=133)$ and physiological responses $(\mathrm{n}=115$, including measures of plant chemistry).

\section{Ecological contexts covered by the evidence base}

Most studies were clustered in northern Fennoscandia (Fig. 4). Together, Norway (excluding Svalbard), Sweden and Finland represented $40 \%$ of all studies (263 out of 662). Given that this region is mainly Subarctic, this contributed to the Subarctic bioclimatic zone being represented by 318 studies, as compared to the 291 studies from actual Arctic bioclimatic zones A-E (see Table 1 for definitions and references for ecological context variables). Other large clusters of studies were found in Svalbard and coastal Alaska (Fig. 4A). 


\section{A Herbivore groups and plant groups}

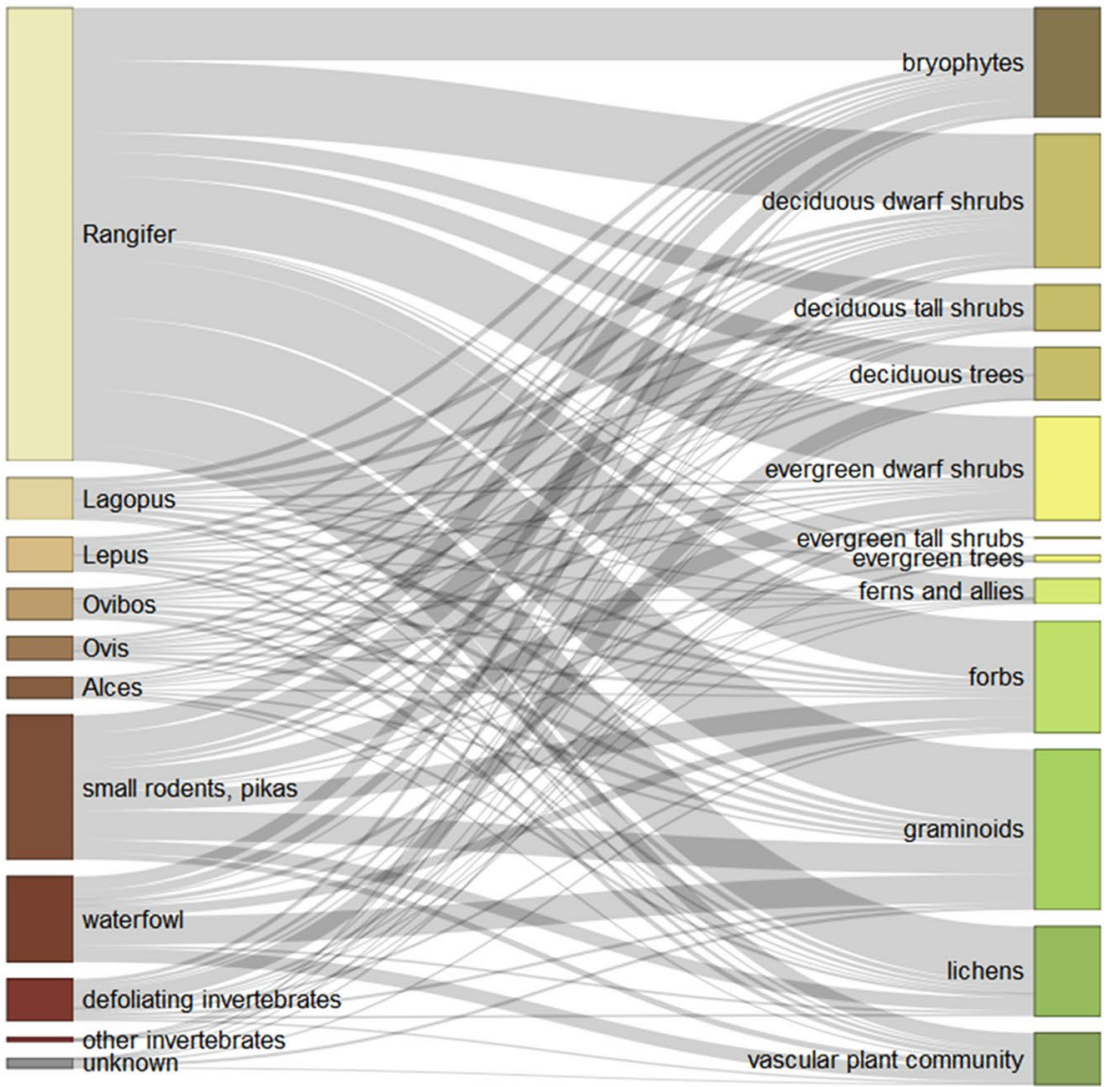

B Herbivore type and plant level $(n=847)$

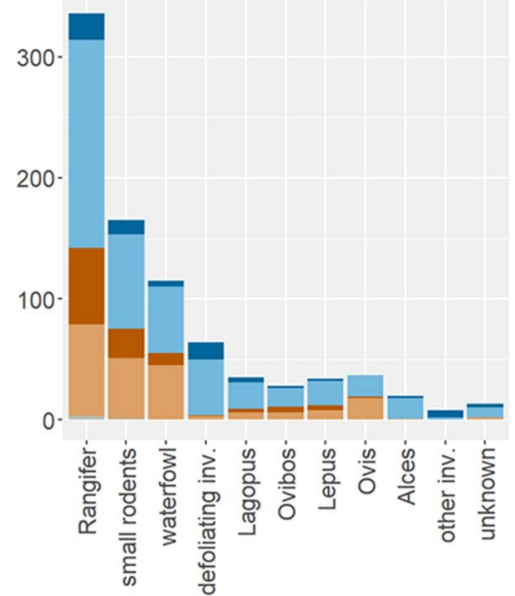

C Herbivore type and study type $(n=777)$

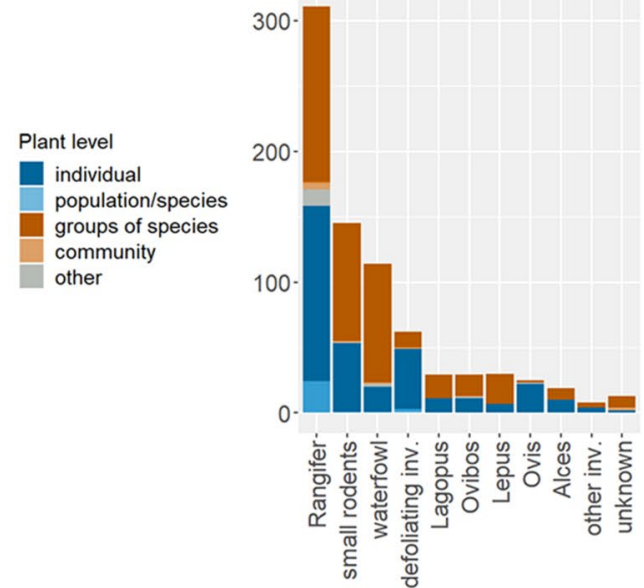

Study type

experimental, field

experimental, remote sensing experimental, greenhouse modelling

observational, field

observational, remote sensing

observational, other

Fig. 3 Herbivore groups, plant groups, and study types. A combines the studies per herbivore group with the plant groups these studies investigated. B shows the count of studies across herbivore group and the level at which results on plants are reported. $\mathbf{C}$ shows the count of studies according to herbivore type and study approach. Herbivore group "defoliating inv." refers to defoliating invertebrate herbivores and "other inv." to other types of invertebrates. The vertebrate herbivores were first divided into three functional groups according to Speed et al. 2019 [37]; the group "small rodents and pikas" is denoted as "small rodents" in B and C. The functional group of larger vertebrates that overwinter above snow was further sub-divided to genera. Sample size refers to unique combinations; for instance, if a study that included several herbivores it is plotted in each herbivore category 


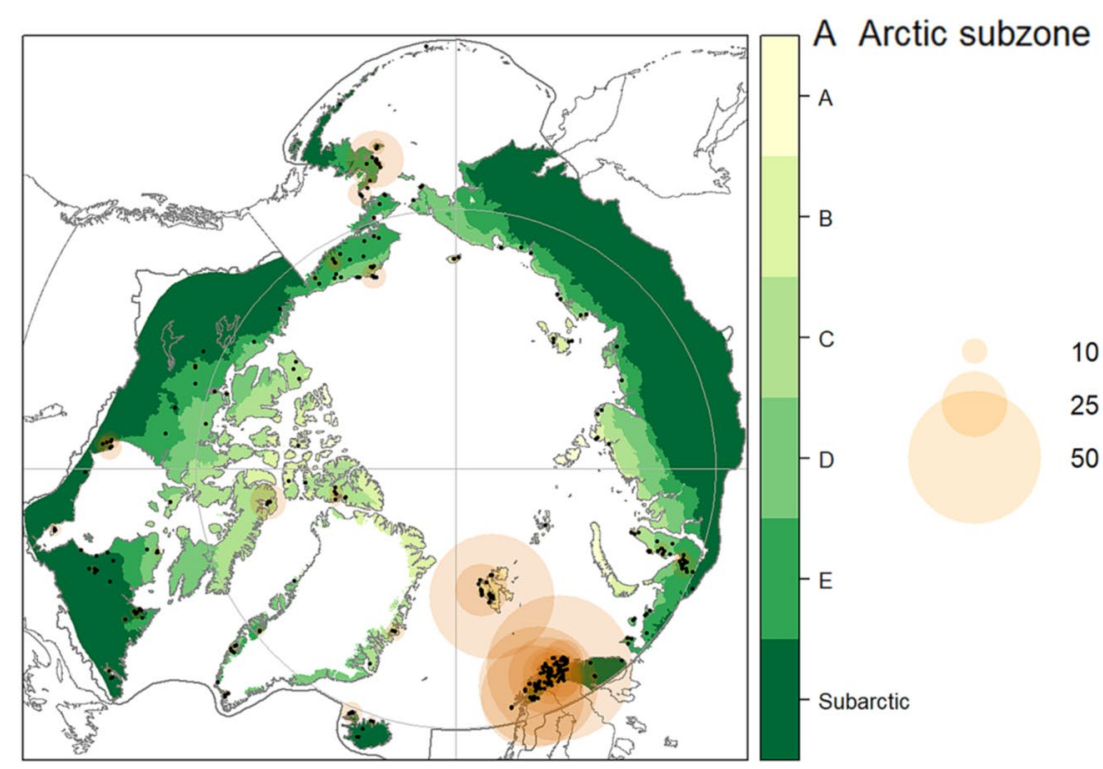

B Temperature anomaly $\left({ }^{\circ} \mathrm{C}\right)$

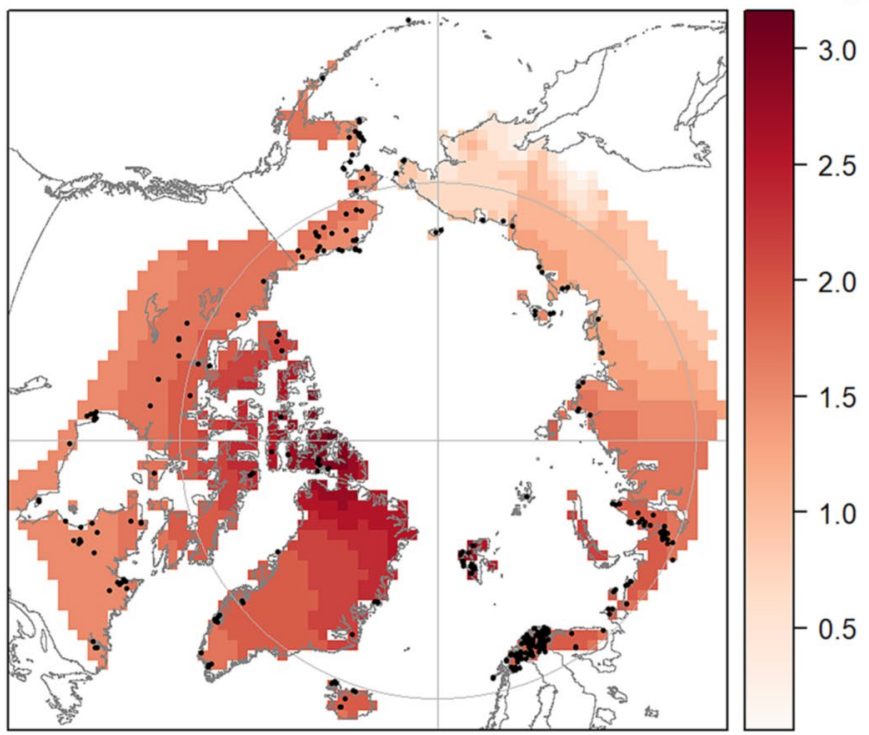

Fig. 4 Spatial distribution of studies around the Arctic tundra biome. A shows Arctic subzones and B temperature anomaly (2000-2020 vs 1951-1980). Studies are shown with black in both panels, in $\mathbf{A}$ also with orange circles showing areas with high densities. In panel A, the colored areas show the five Arctic subzones (A-E; CAVM [92]) and the Subarctic (CAFF/ABA [30]). The thick grey line shows the Arctic boundary defined by CAFF [29]. The study region was delimited within this boundary and areas outside Subarctic areas filtered removed; areas outside study region are shown as white in both panels

Only $9 \%(n=59)$ of studies came from areas that were further than $100 \mathrm{~km}$ inland from the coast (Fig. 5A); thus, herbivore impacts are less well covered by the evidence base in inland Arctic areas. The elevational range of the Arctic was covered relatively well (Fig. 5A). Over onethird (39\%) of the studies were located below $100 \mathrm{~m}$ a.s.l. while the uppermost ones were as high as $1870 \mathrm{~m}$ a.s.l., which reflects well the distribution of elevation across the Arctic. Subarctic studies were conducted at higher elevations, on average, than Arctic studies, as the median elevation for Subarctic studies was $330 \mathrm{~m}$ a.s.l., and $54 \mathrm{~m}$ a.s.l. for studies in the Arctic bioclimatic zones A-E. We used the limit between Subarctic and Arctic to delineate the treeline (Table 1). Frequency of studies was highest in the vicinity of the treeline, illustrated by a median distance of $163 \mathrm{~km}$. 

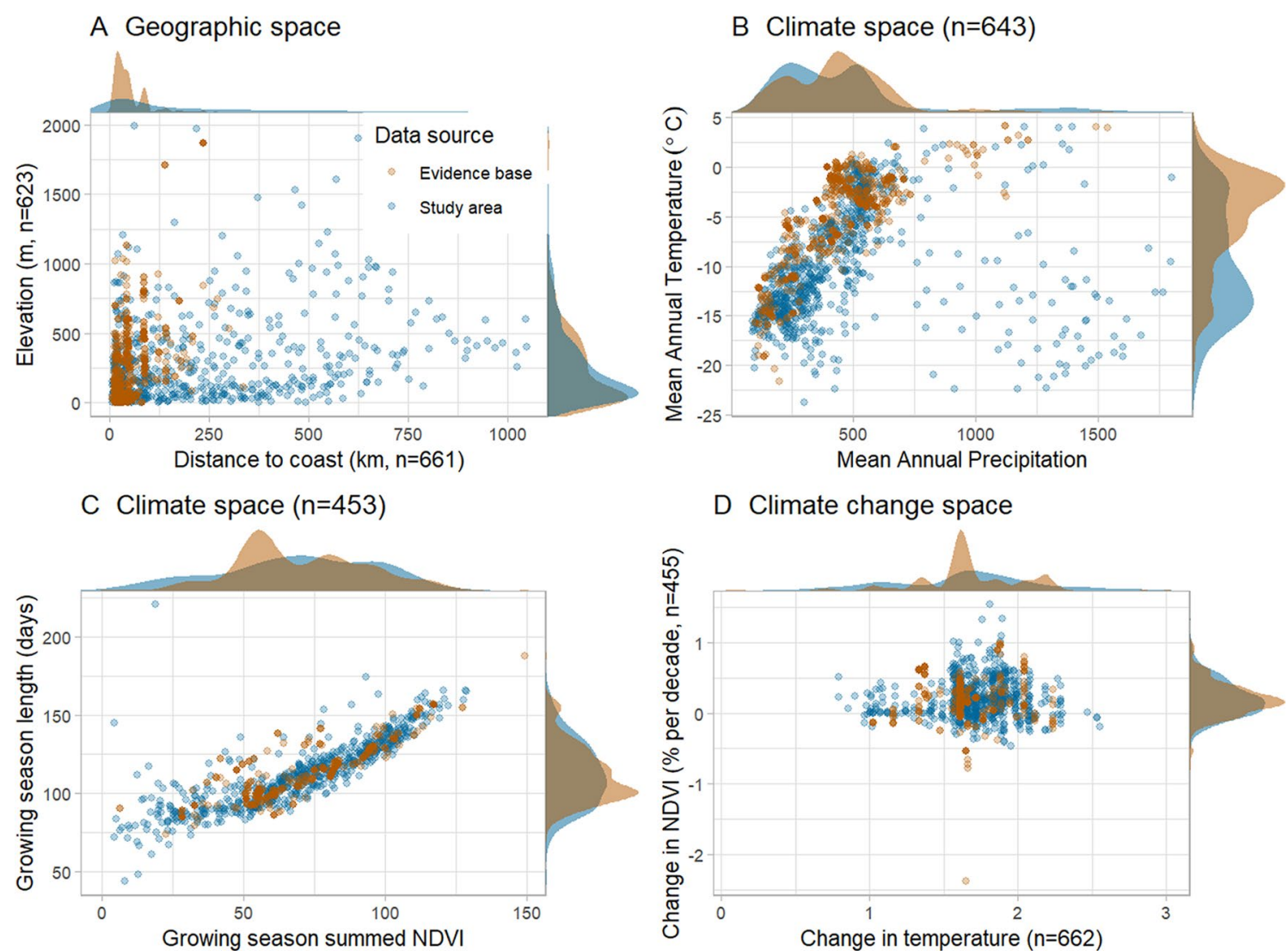

D Climate change space

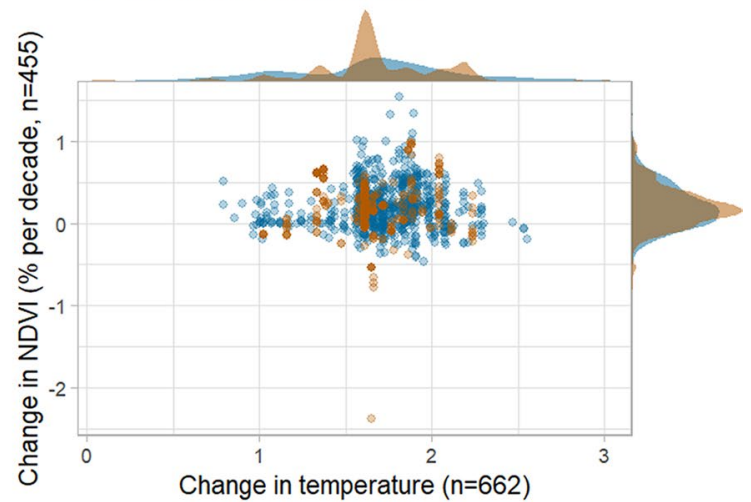

F Human space $(n=656)$
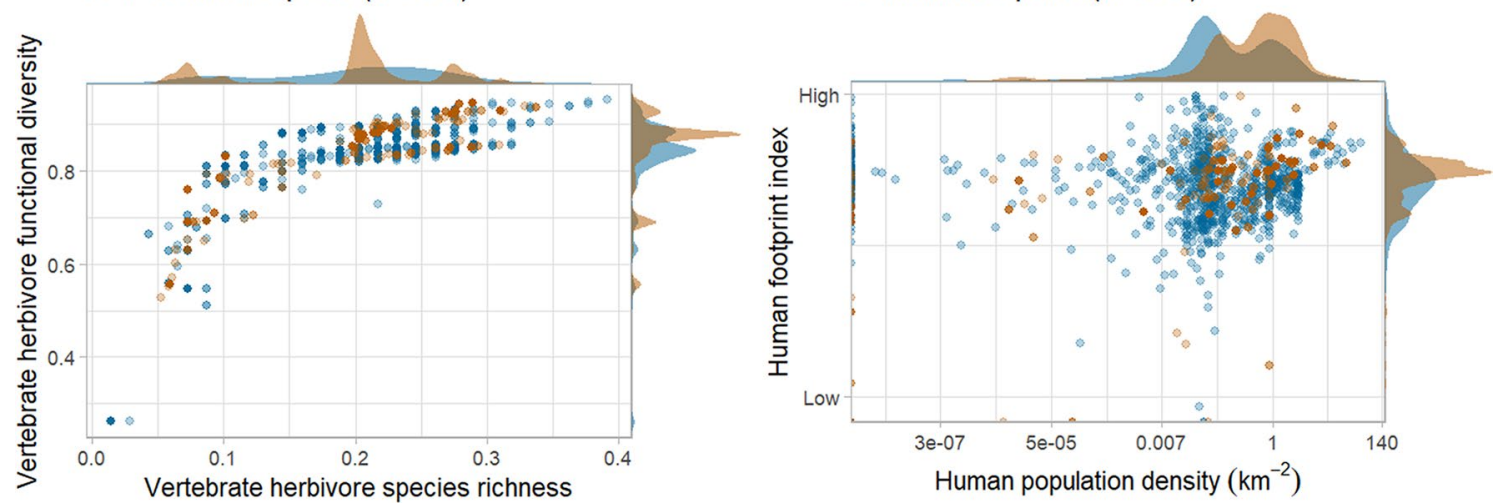

Fig. 5 Studies across ecological context variables. The brown points (and histograms) show data for studies, while blue points (and histograms) describe the range of all ecological contexts across the Arctic study region at $100 \times 100 \mathrm{~km}$ resolution. Sample size refers to the number of studies with data (i.e., non NA-values). When sample size is given next to the figure subtitle it refers to both variables. When it is given along $x$ and $y$ axis titles, it refers to the specific variable. Note that in these cases the histograms are showing all available data for each of the variables, even though the points are not. For example, histogram for "change in temperature" includes all 662 data points even though only 455 can be plotted against change in NDVI, due to missing data for NDVI

Sites with continuous permafrost $(n=295)$ were most common in the evidence base, with the remaining sites being divided into sporadic $(\mathrm{n}=124)$, discontinuous $(n=98)$, and isolated patches $(n=12)$ of permafrost. However, the permafrost data layer (Table 1, [38])
yielded"NA" values for sites south of the permafrostcovered Arctic ( $\mathrm{n}=38$ for Subarctic) and for sites close to the coast in many places of the High Arctic $(n=38$ for bioclimatic zones $\mathrm{A}, \mathrm{B}$, and $\mathrm{C}$ combined). The most common soil types in the evidence base were lithosols 
( $\mathrm{n}=158$, distributed rather evenly between Alaska, Canada, Finland, Norway, Russia and Sweden), podzols $(\mathrm{n}=148$, mainly in Norway and Finland), gleysols $(\mathrm{n}=99$, mainly in Alaska and Russia) and regosols ( $n=63$, only in Canada and Greenland). However, the soil data layer (Table 1, [39]) also resulted in all of the 74 studies on Svalbard having"NA" values for soil data. Thus, the permafrost data and soil type data are not entirely informative at the circumpolar scale.

For many studies $(\mathrm{n}=470)$, no additional disturbances were reported, but the most common types of disturbances were herbivory from non-target herbivores $(n=77)$, fire $(n=33)$, human infrastructure $(n=28)$ and flooding $(\mathrm{n}=18)$.

Studies were overrepresented in warm and moderately wet areas (Fig. 5B, for definitions of the climate variables, see Table 1). For instance, half of the studies were in areas with a mean annual temperature above $-3.7^{\circ} \mathrm{C}$, while the mean annual temperature across the entire study region's land surface was $-11.4{ }^{\circ} \mathrm{C}$. Mean annual precipitation has a bimodal distribution (Fig. 5B), with the upper precipitation mode having a higher proportion of studies than the lower mode, which in turn is more characteristic of the study region. Furthermore, studies were more common in parts of the Arctic with less intra-annual temperature variation. For example, median annual temperature range for the evidence base was $34{ }^{\circ} \mathrm{C}$, but $47{ }^{\circ} \mathrm{C}$ for the study region. Finally, although the studies did cover the range of growing season lengths present in the Arctic, they were scarce in areas with very long or short growing seasons (Fig. 5C). Areas with low vegetation greenness (based on Normalized Difference Vegetation Index, NDVI, Table 1) were also less well covered (Fig. 5C).

The magnitude of recent climate change was represented by the change in average temperature, vegetation greenness and growing season length over the last decades (Table 1). While the studies overrepresented areas of moderate temperature increase, they covered the range of the observed warming (Figs. 4B, 5D). Furthermore, there was good coverage of the range of changes in vegetation greenness and growing season length change (for patterns of the latter, see the Shiny App).

The evidence base covered the range of Arctic vertebrate herbivore diversity in terms of species richness, phylogenetic diversity and functional diversity (Fig. 5E, for the figure of phylogenetic diversity, see Shiny App). Most studies included no description of the food web of the study site beyond vegetation; 490 studies did not mention non-target herbivores, and 631 did not mention predators.

The ecological contexts created by humans were represented by human population density and the human footprint index, which combines human population density with infrastructure and other land uses (Table 1, [4042]). For these variables, the studies covered the range that is present across the Arctic but were concentrated in areas with a higher human footprint and population density (Fig. 5F). In addition, 148 studies reported current and/or historical management of the area, while 22 were reportedly done in protected areas and 35 mentioned a conservation focus of the work.

When looking at the ecological contexts covered by studies targeting different herbivores, we found important geographical biases. For example, in the case of studies on $R$. tarandus, which accounted for approximately half of the entire evidence base of herbivores $(n=349), 75 \%$ of these data came from just three Arctic regions-Fennoscandia, Svalbard and the Yamal Peninsula (combined $n=264$ ) and are thereby biased towards warm and wet areas close to the forest and coast. Similar geographical biases were also found for other groups of herbivores, like waterfowl: among the 128 studies on waterfowl, only six were on the Eurasian continent. These studies were highly clustered at a few intensively studied locations such as Svalbard, La Pérouse Bay, Bylot Island, Akimiski Island, and the Yukon-Kuskokwim Delta. Studies for waterfowl came mainly from coastal lowlands (119 studies at $<150 \mathrm{~m}$ a.s.l., 123 studies within $50 \mathrm{~km}$ from the coast), from the Arctic bioclimatic zones $(A=1$, $\mathrm{B}=4, \mathrm{C}=51, \mathrm{D}=5, \mathrm{E}=30$, Subarctic $=21$ ), and in permafrost covered sites $(\mathrm{n}=96$ studies with continuous permafrost). Studies addressing the functional group of "small rodents and pikas" were most common on the Eurasian continent ( $n=64$ out of the 79 for this group, note that no pikas inhabit this continent). These studies were mainly close to the coast (65 studies within $50 \mathrm{~km}$ from the coast). The 385 studies on vertebrate herbivores other than waterfowl and small rodents (i.e., the functional group "other vertebrates") were spread throughout the Arctic, with only one evidence point further east in Siberia than the Yamal Peninsula (work in the Lena Delta on marmots). These studies covered mainly Subarctic and Low Arctic areas $(n=272$ studies in bioclimatic zone E and Subarctic) and areas close to the coast (229 studies within $50 \mathrm{~km}$ from the coast). The 67 studies on defoliating invertebrates were predominantly one-time studies $(n=49)$ relating to herbivore outbreaks $(n=38)$, at lowland sites with trees $(\mathrm{n}=46$ below $300 \mathrm{~m}$ a.s.l.), and clustered in the warm $\left(\mathrm{n}=55\right.$ with higher than $-5{ }^{\circ} \mathrm{C}$ annual mean temperature) parts of the Arctic with high precipitation ( $\mathrm{n}=60$ with more than $400 \mathrm{~mm}$ annual precipitation), mainly in northern Fennoscandia $(n=47)$ and eastern Canada $(\mathrm{n}=13)$. 


\section{Mapping the validity of studies relevant to the question} Mapping the validity of the studies was not the aim of our systematic map, but we recorded studies with incomplete information regarding their study design. Several studies omitted information describing data sampling to the extent that we were unable to assign the first year of study $(n=45)$, temporal resolution (i.e., how often the data were sampled, $n=27$ ), how large the study area was $(n=156)$, or the scale of sampling plots/units $(n=63$ and 46 for reporting scale and recording scale). We explored visually and with linear regressions whether the proportion of studies with missing information for these variables changed over time, but found support for a decreasing trend only for the extent of spatial scale (effect of year $-0.01[-0.02,-0.00495 \% \mathrm{CI}])$.

We also explored visually whether local (i.e., study area size less than $10 \times 10 \mathrm{~km}$ ) or short-term (i.e., one-year) studies were more common for some of the ecological contexts (Additional file 7: Figures S1 and S2). This comparison revealed no striking patterns. However, Subarctic regions had an evidence base with a balanced mix of small- and large-scale studies, whereas small-scale studies dominated in the Arctic zones $\mathrm{C}$ and $\mathrm{E}$. This difference was further reflected in some of the other variables (e.g. distance to treeline, vegetation greenness and herbivore species richness), presumably because these variables correlate with the bioclimatic zonation.

\section{Limitations of the map}

Accessibility of the grey literature is likely to vary greatly among the Arctic countries. For example, MSc-theses from Russia are usually not available online, whereas MSc-theses from the Nordic countries are routinely deposited in institutional and national online portals (e.g., Norway: bora.uib.no, nora.openaccess.no; Iceland: skemman.is). We assessed this source of bias by tabulating the number of MSc and PhD theses per country, and the number of other grey literature studies per country. A total of 39 student theses were retrieved in our search, 4 BSc theses, $15 \mathrm{MSc}$ theses and $20 \mathrm{PhD}$ theses. Most theses were affiliated with universities in Canada (13) and Sweden (12), followed by Iceland (4) and Norway (3). Other countries included the United States (3), United Kingdom (2), Denmark (1) and Germany (1). No theses were retrieved from Russia. This pattern differs from the total number of studies per country (e.g., Norway having more studies than Canada). However, it is also possible that countries differ in terms of how often theses are published as peer-reviewed articles, and therefore excluded as duplicates.

The data reported by the authors was highly heterogeneous for some context variables. For example, information on temperature and precipitation varied in terms of which variable was reported (such as annual mean, seasonal means, means of warmest and coldest months) and from where data were acquired (the study site, the nearest weather station or from gridded meteorological data). To overcome such heterogeneity, and to acquire data on additional variables that are generally not reported in publications, we used several geospatial data layers to extract variables at the evidence point coordinates (see Table 1 for a list of these variables). While this allows for uniformly defined data across all studies, it also comes with some disadvantages. The precision of geographic coordinates varies among studies, and some studies may thus have been assigned ecological context variable values less accurately than others. Further, geospatial data layers can also have systematic errors in data quality across the Arctic [43], and some geospatial layers gave no data for a substantial proportion of the studies due to data layer resolution or coastline placement. The number of studies with NA values ranged from 0 (extent of recent warming) to 209 (vegetation greenness and growing season length).

Additional potential biases identified during the study coding process were related to the definition of tundra and forest and to inconsistency of defining studies. First, the authors of the reviewed studies described forest in various ways, likely leading to various interpretations by the reviewers coding information from the studies. When in doubt, reviewers inspected Google Earth to assess whether the habitat could be considered an open ecotone forest versus boreal forest, potentially creating some subjectivity in the exclusion/inclusion of particular studies. However, we do not consider this a major concern since only $1 \%$ of studies were excluded due to the study being carried out in boreal forests. Second, our definition of studies left some space for interpretation, especially from complex multi-site multi-habitat studies. While this was ameliorated by having two authors to check and edit all coded data, we acknowledge that it might affect the repeatability of our study.

Our approach does not use within-study replication to weigh the amount of evidence provided within a study. For instance, larger spatial and temporal extents did not correspond to more studies per article, unless the article included several clearly stated different ecological contexts. Thus, several studies with replicates spread across large spatial extents [12] or long time-frames [44] were coded as one study, similarly to local, short-term studies $[45,46]$.

\section{Conclusions}

We present the first synthesis of the circumpolar coverage of the available evidence about the effects of herbivores on Arctic vegetation. We found that there is a growing 
number of studies in the field of Arctic herbivory, but our analysis revealed clear gaps in existing coverage. Similar to previous studies reporting geographic biases in Arctic research [27], we found that the evidence base is geographically biased towards Fennoscandia and Subarctic regions. This translates to an evidence base that is, in terms of ecological context, biased towards areas that are warmer, wetter, relatively close to the coast and treeline and have moderately changing climatic conditions. This bias has direct consequences for the extent to which our current understanding of herbivore impacts on vegetation can be used to guide policy and management decisions across the Arctic and how to focus future research.

\section{Implication for policy/management}

The bias in ecological contexts covered in the current evidence base may limit our ability to generalize the conclusions on herbivore impacts on Arctic vegetation, and more broadly, the management of plant-herbivore interactions. Herbivory by ungulates has repeatedly been suggested to counteract some of the impacts of climate change on tundra vegetation [1, 13, 47-49], and grazing management has been proposed as a potential management tool $[7,12,50]$. Impacts of large herbivores on vegetation are context-dependent [18]. For instance, Rangifer tarandus herbivory is related to different vegetation state changes in Subarctic tall-shrub-tundra and High Arctic graminoid-tundra $[12,51]$, while precipitation appears to be an important determinant of the impacts of Rangifer trampling on lichens $[52,53]$. Thus, generalizations based on an evidence base that is biased towards Subarctic vegetation types and high precipitation, as shown in the current systematic map, are unlikely to be valid throughout the Arctic. Accordingly, for successful implementation of $R$. tarandus grazing as a vegetation management tool in colder and drier parts of the Arctic, as well as further away from the coast and/or forests, such as continental Siberia and North America, a better understanding of $R$. tarandus impact on vegetation in such areas is critical.

However, not all geographical biases in the evidence base represent an ecologically meaningful lack of studies. For example, for actively managed Arctic geese [54-56] studies were scarce in inland areas, at higher elevations, in areas with no permafrost, areas with high temperature seasonality and on the Eurasian continent. However, in this case, the evidence base generally reflects actual goose habitat use, which is typically concentrated on coastal lowlands in the Arctic $[57,58]$. Thus, the existing spatial clusters of studies can provide a good base for local and regional goose management. However, the knowledge gained from these clusters of studies should be applied carefully to management of goose grazing in sites with less represented environmental contexts, such as in permafrost-free Iceland or northern Fennoscandia.

\section{Implication for research}

A rather worrying result in terms of understanding the combined effects of herbivores and climate change is that the evidence base has a notable bias towards areas with moderate warming. Consequently, even though studies do exist across the range of climate change contexts, general conclusions of herbivore impacts on vegetation are likely to be biased to the knowledge gained from moderate climate changes. Arctic herbivores [59-62] and vegetation $[63,64]$ are affected by climate change directly and indirectly, e.g., via changes in phenology and food webs. Thus, there are numerous potential trajectories of plantherbivore interactions in a changing climate, highlighting the need for good coverage across the entire gradient of climatic changes. Our systematic map calls for future studies to prioritize the areas experiencing the most pronounced climate changes but also in those that are more resilient (i.e., those changing the least) to increase our broader understanding and management of the effects of herbivores (see Fig. 4B).

By far, most studies on the effects of herbivores on tundra vegetation focused on vertebrate herbivores, while the evidence base for the effects of invertebrate herbivores on tundra plants remains scant. This knowledge gap on the role of Arctic invertebrate herbivores has been emphasized by recent studies $[65,66]$ and has been traditionally attributed to the lower diversity and abundance of invertebrate herbivores at higher latitudes compared to lower latitudes $[67,68]$. As well, several studies assessed patterns of invertebrate herbivory but not their impacts on plants (e.g., $[65,66,69-72])$, and were therefore excluded from our systematic map. Others, like [48] reported invertebrate herbivory as an additional "disturbance", rather than as the focal herbivore of their study. Most studies on invertebrates focused on outbreaks of defoliating herbivores, mainly in northern Fennoscandia and Canada, east of the Hudson Bay, with only one article from west Greenland [73]. Outbreaks of invertebrate herbivores have been well documented in the forest-tundra ecotone $[61,74]$ and less frequently in tundra [73]. Background invertebrate herbivory (i.e., herbivory at non-outbreak densities) is widespread across the tundra $[65,66]$ but its effects on tundra plants have yet to be thoroughly investigated [70]. Our systematic map also underscores the need for future studies on invertebrate herbivores in the Arctic, in support of other studies that have emphasized the need for long-term monitoring of insect herbivory across the Arctic [75, 76].

According to our systematic map, field experiments commonly use exclosures to study the effects 
of herbivores on tundra vegetation. Consequently, our understanding of the effects of herbivores is largely biased to understanding what happens after herbivores are removed from the system. However, the effects on vegetation of reducing or completely excluding herbivores may not parallel those of increasing herbivore densities [77]. Consequently, exclosure studies to make management recommendations related to herbivores or vegetation should be used with caution. An additional consideration is that, even if most experimental field studies excluded herbivores from experimental plots, they used very different exclosure methods. Methods ranged from fencing off areas to prevent access by larger herbivores (e.g., [78]), to using size-selective exclosures that prevent access by some herbivores but not others (e.g., [47]), or the use of pesticides to exclude invertebrate herbivores (e.g., [79]). Such differences in methodology make syntheses challenging and prevent the exploration of broad-scale patterns and context dependencies in the processes under study, even if the evidence is available (e.g., [80]). Coordinated experiments that use standardized methodologies across broad geographical ranges can partly help overcome this problem [81]. Harmonizing research efforts through the development and use of common protocols will help make results of different studies more comparable, allowing for more robust generalizations across sites and plant-herbivore systems $[82,83]$. However, the implementation of such protocols at existing study sites alone will not solve the issue of some ecological contexts being underrepresented, given the current spatial distribution of Arctic research documented by this study and others [27]. Targeting inclusion of study sites in the underrepresented areas (e.g., High Arctic, inland areas) would provide much-needed data and should be a priority in the future planning of coordinated large-scale studies.

Surprisingly, we found that several studies had major gaps in the description of study design, such as omitting information on which year the fieldwork was done, coordinates of the field site, or which parts of the data were already published. Furthermore, for most variables there appeared to be no improvement in the reporting standards over time, a pattern also observed by Haddaway and Verhoeven [84]. The lack of basic, well-structured study information needed for comparisons, such as covariates or metadata [84, 85], makes individual studies less useful for general knowledge synthesis. This insufficient reporting of methods and results is a common problem in ecology and evolution preventing transparency and repeatability $[84,86]$. We strongly urge authors of future studies on herbivory (and any other ecological investigation) to give clear descriptions of study designs (maps showing hierarchical sites, etc.) and to clearly state whether some parts of the data are spatial or temporal subsets of (or expansions to) already published data. We further suggest that authors consider adding an appendix providing information similar to Additional file 4, describing the study design, measured variables, and the ecological context of the study.

We mapped the ecological contexts in which research on Arctic herbivory has been conducted and demonstrate how it can be used to identify gaps in our knowledge and direct future studies on herbivory in the Arctic. Yet, the analyses conducted offer only broad patterns. The evidence base can be used as a basis for systematic reviews addressing more detailed questions and zooming in to specific ecological contexts, herbivores, plants or herbivore effect types. Furthermore, our list of context variables is not exhaustive. For instance, climate change driven changes in snow conditions affect both herbivores and plants [87-89], and soil temperatures experienced by plants can differ substantially from gridded air temperature data based on measurements $2 \mathrm{~m}$ above ground [90]. Data related to these variables were not available in a format that could be used in a circumpolar synthesis, but once they become available their addition would provide additional insights. As we have made the results available through the interactive Shiny App, they are easily available for exploration and to generate further hypotheses.

Finally, a remaining challenge will be keeping the results up to date. A systematic map represents a substantial investment in time spent writing the protocol, searching and summarizing, and communicating results. Yet, with the ever-increasing number of new studies, systematic maps tend to become outdated fairly quickly. The protocol for this systematic map outlines an idea of a system by which new studies could be submitted to the dataset [28], to increase the longevity and relevance of the systematic map. However, given (i) the amount of manual work related to the preparation of the coded data (minor corrections for typos, grouping of variables, verifications for redundancy), and (ii) the increasing availability of new, relevant geospatial layers, we now believe that such an automatic approach is unlikely to provide robust results with new insights. Rather, regular revisits and updated versions of the original systematic map will be needed (Additional file 1).

\section{Supplementary Information}

The online version contains supplementary material available at https://doi. org/10.1186/s13750-021-00240-0. 
Additional file 1. Additional information on literature searches. ROSES form systematic map.

Additional file 2. Additional information on literature searches. Contains description of search sources including web addressed used, date and language of the search, and search string used in each source. Searches in different languages for the same source are indicated as separate rows. The number of documents retrieved from each source is reported.

Additional file 3. List of articles. Contains all search results retrieved from the literature searches with information on exclusion stage and (for full text stage) reasons for exclusion, and definitions of variables.

Additional file 4. Coding template and description of coded variables. Coding template used for data entry, including descriptions of coded variables, definitions of dropdown menus and references to the spatial data sources for variables extracted from other data sources.

Additional file 5. Coded raw data. Raw data coded from full text studies. This file is compiled with the geospatial data through scripts available https://github.com/JamesDMSpeed/ArcticHerbivorySystematicMap, and the dataset with geospatial data can be downloaded from https://shiny. vm.ntnu.no/users/speed/ArcticHerbivorySystematicMap/.

Additional file 6. Plant functional group data aggregated from raw data. Plant functional group data, aggregated from raw data.

Additional file 7. Additional Figures showing the spatial and temporal extent of studies across ecological context variables.

\section{Acknowledgements}

We thank the participants of the Herbivory Network workshop "Identification of data gaps in tundra herbivory" in Iceland (16.9.2016), and the hands-on working session in the Herbivory Network meeting at Labytnangi, Yamal, Russia (20.9.2019). We thank Virve Ravolainen for contributing to the ideas behind the project. The Herbivory Network is a UArctic Thematic Network.

\section{Authors' contributions}

Conceptualization (EMS, ICB, JDMS, DE, JJ), methodology (EMS, ICB, JDMS, DE, $J J)$, software (JDMS, ALK), formal analysis (JDMS, EMS, EK, ICB), investigation (EMS, ICB, JS, RB, KB, DE, KAH, EK, SA, RGB, GB, IE, RFH, JF, CG, OG, MdH, KH,

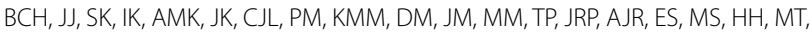
MWT, MV, KEMV, MV, RvdW, MW, NY), data curation (EMS, ICB), writing-original draft (EMS, ICB, JDMS), writing - review and editing (EMS, ICB, JS, RB, KB, $D E, E K, K A H, S A, R G B, G B, I E, R F H, J F, O G, M d H, K H, B C H, J J$, SK, IK, AMK, JK, CJL, PM, KMM, DM, JM, MM, TP, JRP, AJR, ES, MS, MT, MWT, MV, KEMV, MV, RvdW, MW, NY), visualization (EMS, ICB, JDMS, ALK), project administration (EMS), funding acquisition (EMS, ICB, JDMS). All authors read and approved the final manuscript.

\section{Funding}

FRAM — High North Research Centre for Climate and the Environment supported this work with funding for two workshops (project name: "The status of evidence for herbivory in Arctic tundra ecosystems-A protocol for a systematic map"). Funding from the Terrestrial Working Group of the International Arctic Science Committee (IASC) was received to organize the Herbivory Network meetings in Iceland in 2016 and in Yamal in 2019, where this project was worked upon. PM was supported by GACR 17-20839S, EK by Jane and Aatos Erkko Foundation (via Research Centre for Ecological Change), OG by the French Polar Institute-IPEV (program 1036 Interactions), ICB received funding from the Icelandic Research Fund (TUNDRAsalad; grant nr. 217754). JDMS was supported by the Research Council of Norway (262064), IK was funded through the Durham ARCTIC DTP by the Leverhulme Trust. The publication charges for this article have been funded by a grant from the publication fund of UiT The Arctic University of Norway.

\section{Availability of data and materials}

All data is available for download as supporting information as well as from https://shiny.vm.ntnu.no/users/speed/ArcticHerbivorySystematicMap/.

\section{Declarations}

Ethics approval and consent to participate

Not applicable.

\section{Consent for publication}

Not applicable.

\section{Competing interests}

The authors have no competing interests to declare.

\section{Author details}

${ }^{1}$ Department of Arctic and Marine Biology, UiT-The Arctic University of Norway, 9037 Tromsø, Norway. ${ }^{2}$ Faculty of Environmental and Forest Sciences, Agricultural University of Iceland, Keldnaholt, 112 Reykjavík, Iceland. ${ }^{3}$ Centre for Biodiversity Dynamics, Department of Biology, Norwegian University of Science and Technology, 7491 Trondheim, Norway. ${ }^{4}$ Department of Biological and Environmental Sciences, University of Gothenburg, PO Box 461, 405 30 Gothenburg, Sweden. ${ }^{5}$ Human-Environment Systems, Boise State University, Boise, ID 83725, USA. ' Organismal and Evolutionary Research Programme, University of Helsinki, 00014 Helsinki, Finland. 'Department of Natural History, NTNU University Museum, Norwegian University of Science and Technology, 7491 Trondheim, Norway. ${ }^{8}$ Dynamics of Arctic Ecosystems Lab, Arctic Research Station, Institute of Plant and Animal Ecology Ural Branch of Russian Academy of Sciences, Zelenaya Gorka Str., 21, Labytnangi 629400, Russia. ${ }^{9}$ Department of Earth Sciences, University of Gothenburg, 40530 Gothenburg, Sweden.

${ }^{10}$ Gothenburg Global Biodiversity Centre, 40530 Gothenburg, Sweden. ${ }^{11}$ Department of Botany, Institute of Ecology and Earth Sciences, University of Tartu, 51005 Tartu, Estonia. ${ }^{12}$ Norwegian Polar Institute, Fram Centre, 9296 Tromsø, Norway. ${ }^{13}$ Ecology, Evolution, Ecosystems and Society, Dartmouth College, Hanover, NH 03755, USA. ${ }^{14}$ Department of Biological Sciences, Boise State University, Boise, ID 83725, USA. ${ }^{15}$ Centre d'études Nordiques and Plant Science Department, Université Laval, 2425 rue de l'Agriculture, Québec City, Québec, Canada. ${ }^{16}$ UMR 6249 Chrono-Environnement, Université de Bourgogne Franche-Comté, 25000 Besançon, France. ${ }^{17}$ Groupe de Recherche en Ecologie Arctique, 21440 Francheville, France. ${ }^{18}$ European Forest Institute, Yliopistokatu 6 B, 80100 Joensuu, Finland. ${ }^{19}$ Department of Physical Geography and Ecosystem Science, Lund University, Sölvegaten 12, 22362 Lund, Sweden. ${ }^{20}$ Department of Arctic Ecology, Norwegian Institute for Nature Research, Fram Centre, 9297 Tromsø, Norway. ${ }^{21}$ Centre for Ecological and Evolutionary Synthesis, University of Oslo, Oslo, Norway. ${ }^{22}$ Department of Biosciences, University of Durham, Stockton Road, Durham DH1 3LE, UK. ${ }^{23}$ Department of Biology, Washington University in St. Louis, St. Louis, MO 63130, USA. ${ }^{24}$ The Arctic Institute, Washington, DC 20009, USA. ${ }^{25}$ School of Geography and the Environment, University of Oxford, Oxford OX13QY, UK. ${ }^{26}$ School of Environmental Science, Simon Fraser University, Burnaby, BC V5A 1S6, Canada. ${ }^{27}$ Institute of Hydrobiology, Biology Centre of Czech Academy of Sciences, Na Sadkach 7, 37005 Ceske Budejovice, Czech Republic. ${ }^{28}$ Faculty of Science, University of South Bohemia, Branisovska 1760, 37005 Ceske Budejovice, Czech Republic. ${ }^{29}$ Department of Forestry and Wildlife Management, Inland Norway University of Applied Sciences, 2418 Elverum, Norway. ${ }^{30}$ Department of Ecology and Environmental Science, Umeå University, Linnaeus väg 6, 90187 Umeå, Sweden. ${ }^{31}$ Department of Biology, University of Freiburg, 79104 Freiburg, Germany. ${ }^{32}$ NASA Ames Research Center, Moffett Field, CA 94035, USA. ${ }^{33}$ Bay Area Environmental Research Institute, Moffett Field, CA 94035, USA. ${ }^{34}$ Center for Ecosystem Science and Society, Northern Arizona University, Flagstaff, AZ 86011, USA. ${ }^{35}$ Department of Biological Sciences, Northern Arizona University, Flagstaff, AZ 86011, USA. ${ }^{36}$ Wildlife Ecology and Health Group (WE\&H) and Servei d'Ecopatologia de Fauna Salvatge (SEFaS), Departament de Medicina I Cirurgia Animals, Universitat Autònoma de Barcelona, Bellaterra, 08193 Barcelona, Spain. ${ }^{37}$ Environment and Natural Resources, University of Iceland, Sturlugata 7, 101, Reykjavík, Iceland. ${ }^{38}$ Institute of Zoology, Zoological Society of London, Regent's Park, London NW1 4RY, UK. ${ }^{39}$ Ecology and Genetics Research Unit, University of Oulu, P. O. Box 3000, 90014 Oulu, Finland. ${ }^{40}$ Arctic Centre, University of Lapland, P. O. Box 122, 96101 Rovaniemi, Finland. ${ }^{41}$ Department of Ecology, Swedish University of Agricultural Sciences (SLU), Ulls väg 16, 75651 Uppsala, Sweden. ${ }^{42}$ Department of Ecology, Evolution, and Behavior, University of Minnesota, 140 Gortner Laboratory, 1479 Gortner Ave., St. Paul, MN 55108, USA. 
Received: 3 May 2021 Accepted: 25 September 2021

Published: 14 October 2021

\section{References}

1. Ims RA, Ehrich D. Terrestrial ecosystems. In: Meltofte H, editor. Arctic biodiversity assessment. Status and trends in arctic biodiversity. Akureyri: Conservation of Arctic Flora and Fauna; 2013.

2. Forbes BC, Stammler F, Kumpula T, Meschtyb N, Pajunen A, Kaarlejärvi E. High resilience in the Yamal-Nenets social-ecological system, west Siberian Arctic. Russia PNAS. 2009;106(52):22041-8.

3. Hovelsrud GK, Poppel B, Oort BV, Reist JD. Arctic societies, cultures, and peoples in a changing cryosphere. Ambio. 2011;40(sup 1):100-10.

4. Huntington HP. Provisioning and cultural services. In: Meltofte $\mathrm{H}$, editor. Arctic biodiversity assessment. Status and trends in arctic biodiversity. Akureyri: Conservation of Arctic Flora and Fauna; 2013.

5. Vuojala-Magga T, Turunen MT. Sámi reindeer herders' perspective on herbivory of subarctic mountain birch forests by geometrid moths and reindeer: a case study from northernmost Finland. Springerplus. 2015;4(1):134

6. Karlsen SR, Jepsen JU, Odland A, Ims RA, Elvebakk A. Outbreaks by canopy-feeding geometrid moth cause state-dependent shifts in understorey plant communities. Oecologia. 2013;173(3):859-70.

7. Biuw M, Jepsen JU, Cohen J, Ahonen SH, Tejesvi M, Aikio S, Wali PR, Vindstad OPL, Markkola A, Niemela P, Ims RA. Long-term impacts of contrasting management of large ungulates in the Arctic tundra-forest ecotone: Ecosystem structure and climate feedback. Ecosystems. 2014;17(5):890-905.

8. Tuomi M, Väisänen M, Ylänne H, Brearley FQ, Barrio IC, Bråthen KA, Eischeid I, Forbes BC, Jónsdóttir IS, Kolstad AL. Stomping in silence: Conceptualizing trampling effects on soils in polar tundra. Funct Ecol. 2020:35:306-17.

9. Petit Bon M, Inga KG, Jónsdóttir IS, Utsi TA, Soininen EM, Bråthen KA. Interactions between winter and summer herbivory affect spatial and temporal plant nutrient dynamics in tundra grassland communities. Oikos. 2020;129:1229-42.

10. Bråthen K, Ims R, Yoccoz N, Fauchald P, Tveraa T, Hausner V. Induced shift in ecosystem productivity? Extensive scale effects of abundant large herbivores. Ecosystems. 2007;10(5):773-89.

11. Tuomi M, Stark S, Hoset KS, Väisänen M, Oksanen L, Murguzur FJ, Tuomisto H, Dahlgren J, Bråthen KA. Herbivore effects on ecosystem process rates in a low-productive system. Ecosystems. 2019;22(4):827-43.

12. Bråthen KA, Ravolainen VT, Stien A, Tveraa T, Ims RA. Rangifer management controls a climate-sensitive tundra state transition. Ecol Appl. 2017:27(8):2416-27.

13. Olofsson J, Oksanen L, Callaghan T, Hulme PE, Oksanen T, Suominen O. Herbivores inhibit climate-driven shrub expansion on the tundra. Glob Change Biol. 2009;15(11):2681-93.

14. Wielgolaski FE, Hofgaard A, Holtmeier F-K. Sensitivity to environmental change of the treeline ecotone and its associated biodiversity in European mountains. Clim Res. 2017;73:151-66.

15. Maron JL, Crone E. Herbivory: effects on plant abundance, distribution and population growth. PRSB. 2006;273(1601):2575-84

16. Moles AT, Bonser SP, Poore AG, Wallis IR, Foley WJ. Assessing the evidence for latitudinal gradients in plant defence and herbivory. Funct Ecol. 2011:25(2):380-8

17. Olofsson J, Moen J, Oksanen L. Effects of herbivory on competition intensity in two arctic-alpine tundra communities with different productivity. Oikos. 2002;96(2):265-72.

18. Bernes C, Bråthen KA, Forbes BC, Speed JD, Moen J. What are the impacts of reindeer/caribou (Rangifer tarandus L.) on arctic and alpine vegetation? A systematic review. Environ Evid. 2015:4(1):4

19. Hansen BB, Lorentzen JR, Welker JM, Varpe $\varnothing$, Aanes R, Beumer LT, Pedersen $\AA \varnothing$. Reindeer turning maritime: Ice-locked tundra triggers changes in dietary niche utilization. Ecosphere. 2019;10(4):e02672.

20. Srivastava DS, Jefferies R. Mosaics of vegetation and soil salinity: a consequence of goose foraging in an arctic salt marsh. Can J Bot. 1995;73(1):75-83
21. Hik D, Jefferies $R$. Increases in the net above-ground primary production of a salt-marsh forage grass: a test of the predictions of the herbivoreoptimization model. J Ecol. 1990;78:180-95.

22. Tape KD, Jones BM, Arp CD, Nitze I, Grosse G. Tundra be dammed: beaver colonization of the Arctic. Glob Change Biol. 2018;24(10):4478-88.

23. Tape KD, Gustine DD, Ruess RW, Adams LG, Clark JA. Range expansion of moose in arctic Alaska linked to warming and increased Shrub Habitat. PLOS ONE. 2016;11(4):e0152636.

24. Vindstad OPL, Jepsen JU, Ek M, Pepi A, Ims RA. Can novel pest outbreaks drive ecosystem transitions in northern-boreal birch forest? J Ecol. 2019;107(3):1141-53.

25. Ravolainen VT, Brathen KA, Ims RA, Yoccoz NG, Henden JA, Killengreen ST. Rapid, landscape scale responses in riparian tundra vegetation to exclusion of small and large mammalian herbivores. Basic Appl Ecol. 2011;12:643-53.

26. Barrio IC, Bueno CG, Gartzia M, Soininen EM, Christie KS, Speed J, Ravolainen V, Forbes BC, Gauthier G, Horstkotte T, Hoset KS, Høye TT, Jónsdóttir IS, Lévesque E, Mörsdorf M, Olofsson J, Wookey PA, Hik DS. Biotic interactions mediate patterns of herbivore diversity in the Arctic. Glob Ecol Biogeogr. 2016;25:1108-18.

27. Metcalfe DB, Hermans TD, Ahlstrand J, Becker M, Berggren M, Björk RG, Björkman MP, Blok D, Chaudhary N, Chisholm C. Patchy field sampling biases understanding of climate change impacts across the Arctic. Nature Ecol Evol. 2018;2(9):1443-8.

28. Soininen EM, Barrio I, Jepsen JU, Ehrich D, Ravolainen VT, Speed JDM Evidence of effects of herbivory on Arctic vegetation: a systematic map protocol. Env Evi. 2018;7(1):23

29. Arctic Council, Conservation of Arctic Flora and Fauna Working Group. Boundary for Conservation of Arctic Flora and Fauna (CAFF) working group of the Arctic Council; 2017.

30. Arctic Biodiversity Assesment. Boundaries of the geographic area covered by the Arctic Biodiversity Assessment. Includes sub, low and high Arctic bounbaries; 2001. http://geo.abds.is/geonetwork/f0eb86a7-e408-41389432-dedb991f13d1. Accessed 23 Jun 2020

31. Arctic Council, Conservation of Arctic Flora and Fauna Working Group, CAFF Map No.10_distribution of major vegetation zones and level of protection in the Arctic; 1996.

32. Cohen J. A coefficient of agreement for nominal scales. Educ Psych Meas. 1960;20:37-46

33. McHugh ML. Interrater reliability: the kappa statistic. Bioch Med. 2012;22(3):276-82.

34. Haddaway NR, Macura B, Whaley P, Pullin AS. ROSES RepOrting standards for Systematic Evidence Syntheses: pro forma, flow-diagram and descriptive summary of the plan and conduct of environmental systematic reviews and systematic maps. Env Evi. 2018;7:4-11.

35. Bernes C, Macura B, Jonsson BG, Junninen K, Müller J, Sandström J, Lõhmus A, Macdonald E. Manipulating ungulate herbivory in temperate and boreal forests: effects on vegetation and invertebrates. A systematic review. Environ Evid. 2018;7(1):13.

36. Winston Chang, Joe Cheng, JJ Allaire, Xie Y, McPherson J. shiny: Web Application Framework for R. R package version 1.5.0; 2020

37. Speed JD, Skjelbred IA, Barrio IC, Martin MD, Berteaux D, Bueno CG, Christie KS, Forbes BC, Forbey J, Fortin D. Trophic interactions and abiotic factors drive functional and phylogenetic structure of vertebrate herbivore communities across the Arctic tundra biome. Ecography. 2019;42(6):1152-63.

38. Brown J, Ferrians O, Heginbottom JA, Melnikov E. Circum-Arctic map of permafrost and ground-ice conditions, version 2. Boulder: NSIDC: National Snow and Ice Data Center; 2002.

39. FAO-UN_L Land and Water Division (CBL), Digital soil map of the world: 2007

40. Center for International Earth Science Information Network-CIESINColumbia University. Gridded Population of the World, Version 4 (GPWv4): Population Density, Revision 11; 2018; Human population density; 2015. http://www.fao.org/soils-portal/data-hub/soil-maps-and-databases/ faounesco-soil-map-of-the-world/en/. Accessed 21 Nov 2020.

41. Venter O, Sanderson EW, Magrach A, Allan JR, Beher J, Jones KR, Possingham HP, Laurance WF, Wood P, Fekete BM, Levy MA, Watson JE. Last of the wild project, version 3 (LWP-3): 2009 human footprint, 2018 release. Palisades: NASA Socioeconomic Data and Applications Center (SEDAC); 2018 
42. Venter O, Sanderson EW, Magrach A, Allan JR, Beher J, Jones KR, Possingham HP, Laurance WF, Wood P, Fekete BM, Levy MA, Watson JE. Global terrestrial human footprint maps for 1993 and 2009. Sci Data. 2016:3:160067.

43. Myers-Smith IH, Kerby JT, Phoenix GK, Bjerke JW, Epstein HE, Assmann JJ, John C, Andreu-Hayles L, Angers-Blondin S, Beck PS. Complexity revealed in the greening of the Arctic. Nature Clim Change. 2020;10(2):106-17.

44. Bety J, Graham-Sauve M, Legagneux P, Cadieux MC, Gauthier G. Fading indirect effects in a warming arctic tundra. Curr Zool. 2014;60(2):189-202.

45. Mosbacher JB, Michelsen A, Stelvig M, Hjermstad-Sollerud H, Schmidt NM. Muskoxen modify plant abundance, phenology, and nitrogen dynamics in a High Arctic fen. Ecosystems. 2019;22(5):1095-107.

46. Soininen EM, Hübner CE, Jonsdottir IS. Food selection by barnacle geese (Branta leucopsis) in an Arctic pre-breeding area. Polar Res. 2010;29(3):404-12.

47. Ravolainen VT, Bråthen KA, Yoccoz NG, Nguyen JK, Ims RA. Complementary impacts of small rodents and semi-domesticated ungulates limit tall shrub expansion in the tundra. J Appl Ecol. 2014;51(1):234-41.

48. Post E, Pedersen C. Opposing plant community responses to warming with and without herbivores. PNAS. 2008;105(34):12353-8.

49. Vowles T, Björk RG. Implications of evergreen shrub expansion in the Arctic. J Ecol. 2019;107(2):650-5.

50. Verma M, To Bühne HS, Lopes M, Ehrich D, Sokovnina S, Hofhuis SP, Pettorelli N. Can reindeer husbandry management slow down the shrubification of the Arctic? J Environ Manag. 2020:267:1 10636.

51. van der Wal R. Do herbivores cause habitat degradation or vegetation state transition? Evidence from the tundra. Oikos. 2006;1 14:177-86.

52. Cooper EJ, Smith FM, Wookey PA. Increased rainfall ameliorates the negative effect of trampling on the growth of High Arctic forage lichens. Symbiosis. 2001;31:153-71.

53. Heggenes J, Odland A, Chevalier T, Ahlberg J, Berg A, Larsson H, Bjerketvedt DK. Herbivore grazing — or trampling? Trampling effects by a large ungulate in cold high-latitude ecosystems. Ecol Evol. 2017;7(16):6423-31.

54. Alisauskas RT, Rockwell RF, Dufour KW, Cooch EG, Zimmerman G, Drake KL, Leafloor JO, Moser TJ, Reed ET. Harvest, survival, and abundance of midcontinent lesser snow geese relative to population reduction efforts. Wildl Monog. 2011;179(1):1-42.

55. Lefebvre J, Gauthier G, Giroux J-F, Reed A, Reed ET, Bélanger L. The greater snow goose Anser caerulescens atlanticus: managing an overabundant population. Ambio. 2017;46(2):262-74.

56. Madsen J, Williams JH, Johnson FA, Tombre IM, Dereliev S, Kuijken E. Implementation of the first adaptive management plan for a European migratory waterbird population: the case of the Svalbard pink-footed goose Anser brachyrhynchus. Ambio. 2017;46(2):275-89.

57. Speed JDM, Woodin SJ, Tommervik H, Tamstorf MP, Van der Wal R. Predicting habitat utilization and extent of ecosystem disturbance by an increasing herbivore population. Ecosystems. 2009;12:349-59.

58. Tape KD, Flint PL, Meixell BW, Gaglioti BV. Inundation, sedimentation, and subsidence creates goose habitat along the Arctic coast of Alaska. Environ Res Lett. 2013;8(4):045031.

59. Doiron M, Gauthier G, Lévesque E. Trophic mismatch and its effects on the growth of young in an Arctic herbivore. Glob Change Biol. 2015;21(12):4364-76.

60. Fauchald P, Park T, Tømmervik H, Myneni R, Hausner VH. Arctic greening from warming promotes declines in caribou populations. Sci Adv. 2017:3(4):e1601365.

61. Jepsen JU, Hagen SB, Ims RA, Yoccoz NG. Climate change and outbreaks of the geometrids Operophtera brumata and Epirrita autumnata in subarctic birch forest: evidence of a recent outbreak range expansion. J Anim Ecol. 2008;77(2):257-64.

62. Hansen BB, Pedersen Å $\varnothing$, Peeters B, Le Moullec M, Albon SD, Herfindal I, Sæther BE, Grøtan V, Aanes R. Spatial heterogeneity in climate change effects decouples the long-term dynamics of wild reindeer populations in the high Arctic. Glob Change Biol. 2019;25(11):3656-68.

63. Gauthier G, Bêty J, Cadieux MC, Legagneux P, Doiron M, Chevallier C, Lai S, Tarroux A, Berteaux D. Long-term monitoring at multiple trophic levels suggests heterogeneity in responses to climate change in the Canadian Arctic tundra. PRSB. 2013;368:20120482.

64. Jepsen JU, Biuw M, Ims RA, Kapari L, Schott T, Vindstad OPL, Hagen SB. Ecosystem impacts of a range expanding forest defoliator at the foresttundra ecotone. Ecosystems. 2013;16(4):561-75.
65. Barrio IC, Lindén E, Beest MT, Olofsson J, Rocha A, Soininen EM, Alatalo $J M$, Andersson T, Asmus A, Boike J, Bråthen KA, Bryant JP, Buchwal A, Bueno CG, Christie KS, Denisova YV, Egelkraut D, Ehrich D, Fishback LA, Forbes BC, Gartzia M, Grogan P, Hallinger M, Heijmans MMPD, Hik DS, Hofgaard A, Holmgren M, Høye TT, Huebner DC, Jónsdóttir IS, Kaarlejärvi E, Kumpula T, Lange CYMJG, Lange J, Lévesque E, Limpens J, Macias-Fauria M, Myers-Smith I, Nieukerken EJV, Normand S, Post ES, Schmidt NM, Sitters J, Skoracka A, Sokolov A, Sokolova N, Speed JDM, Street LE, Sundqvist MK, Suominen O, Tananaev N, Tremblay JP, Urbanowicz C, Uvarov SA, Watts D, Wilmking M, Wookey PA, Zimmermann HH, Zverev V, Kozlov MV. Background invertebrate herbivory on dwarf birch (Betula glandulosanana complex) increases with temperature and precipitation across the tundra biome. Pol Biol. 2017:40(11):2265-78.

66. Rheubottom SI, Barrio IC, Kozlov MV, Alatalo JM, Andersson T, Asmus AL, Baubin C, Brearley FQ, Egelkraut DD, Ehrich D, Gauthier G, Jónsdóttir IS, Konieczka S, Lévesque E, Olofsson J, Prevéy JS, G ST, Sokolov A, Sokolova N, Sokovnina S, Speed JDM, Suominen O, Zverev V, Hik DS. Hiding in the background: community-level patterns in invertebrate herbivory across the tundra biome. Pol Biol. 2019;42(10):1881-97.

67. Danks HV. Insect plant interactions in arctic regions. Rev d'Entomologie du Québec. 1986;31:52-75.

68. Haukioja E. Invertebrate herbivory at tundra sites. In: Bliss LC, Heal OW, Moore JJ, editors. Tundra ecosystems: a comparative analysis. New York: Cambridge University Press; 1981. p. 547-55.

69. Hansen J, Topp-Jørgensen E, Christensen TRE. Zackenberg Ecological research operations 21st annual report, 2015, Aarhus University, DCEDanish Centre for Environment and Energy; 2017.

70. Kozlov MV, Filippov BY, Zubrij NA, Zverev V. Abrupt changes in invertebrate herbivory on woody plants at the forest-tundra ecotone. Pol Biol. 2015;38(7):967-74.

71. Kuczyński L, Skoracka A. Spatial distribution of galls caused by Aculus tetanothrix (Acari: Eriophyoidea) on arctic willows. Exp App Acar. 2005;36(4):277-89.

72. Jensen LM, Rasch M. Zackenberg ecological research operations, 15th annual report, 2009. 2010.

73. Lund M, Raundrup K, Westergaard-Nielsen A, López-Blanco E, Nymand J, Aastrup P. Larval outbreaks in West Greenland: instant and subsequent effects on tundra ecosystem productivity and $\mathrm{CO} 2$ exchange. Ambio. 2017;46(1):26-38.

74. Kaukonen M, Ruotsalainen AL, Wäli PR, Männistö MK, Setälä H, Saravesi K, Huusko K, Markkola A. Moth herbivory enhances resource turnover in subarctic mountain birch forests? Ecology. 2013:94(2):267-72.

75. Schmidt NM, Hardwick B, Gilg O, Høye TT, Krogh PH, Meltofte H, Michelsen A, Mosbacher JB, Raundrup K, Reneerkens J, Stewart L, Wirta $H$, Roslin T. Interaction webs in arctic ecosystems: determinants of arctic change? Ambio. 2017:46(1):12-25.

76. Gillespie MA, Alfredsson M, Barrio IC, Bowden JJ, Convey P, Culler LE, Coulson SJ, Krogh PH, Koltz AM, Koponen S, Loboda S. Status and trends of terrestrial arthropod abundance and diversity in the North Atlantic region of the Arctic. Ambio. 2020;49(3):718-31.

77. Olofsson J. Short- and long-term effects of changes in reindeer grazing pressure on tundra heath vegetation. J Ecol. 2006;94(2):431-40.

78. Francini G, Liiri M, Männistö M, Stark S, Kytöviita M-M. Response to reindeer grazing removal depends on soil characteristics in low Arctic meadows. Appl Soil Ecol. 2014;76:14-25.

79. Wheeler JA, Hermanutz L, Marino PM. Feathermoss seedbeds facilitate black spruce seedling recruitment in the forest-tundra ecotone (Labrador, Canada). Oikos. 2011;120(8):1263-71.

80. Vicca S, Gilgen AK, Camino Serrano M, Dreesen F, Dukes J, Estiarte M, Gray S, Guidolotti G, Hoeppner S, Leakey A. Urgent need for a common metric to make precipitation manipulation experiments comparable. New Phytol. 2012;195(3):518-22.

81. Borer ET, Harpole WS, Adler PB, Lind EM, Orrock JL, Seabloom EW, Smith $M D$. Finding generality in ecology: a model for globally distributed experiments. Met Ecol and Evol. 2014;5(1):65-73.

82. Barrio I, Hik D, Jónsdóttir I, Bueno C, Mörsdorf M, Ravolainen V. Herbivory network: an international, collaborative effort to study herbivory in Arctic and alpine ecosystems. Pol Sci. 2016;10(3):297-302.

83. Barrio IC, Ehrich D, Soininen EM, Ravolainen VT, Bueno CG, Gilg O, Koltz AM, Speed JDM, Hik DS, Mörsdorf M, Alatalo JM, Angerbjörn A, Bêty J, Bollache L, Boulanger-Lapointe N, Brown GS, Eischeid I, Giroux MA, Hájek 
T, Hansen BB, Hofhuis S, Lamarre J-F, Lang J, Latty C, Lecomte N, Macek P, McKinnon L, Myers-Smith HI, Pedersen Å, Prevéy JS, Roth JD, Saalfeld ST, Schmidt NM, Smith P, Sokolov A, Sokolova N, Stolz C, van Bemmelen R, Varpe $D$, Woodard PF, Jónsdóttir IS. Developing common protocols to measure tundra herbivory across spatial scales. Arc Sci. e-First. https://doi. org/10.1139/as-2020-0020

84. Haddaway NR, Verhoeven JTA. Poor methodological detail precludes experimental repeatability and hampers synthesis in ecology. Ecol Evo. 2015:5(19):4451-4.

85. Gerstner K, Moreno-Mateos D, Gurevitch J, Beckmann M, Kambach S, Jones HP, Seppelt R. Will your paper be used in a meta-analysis? Make the reach of your research broader and longer lasting. Met Ecol Evol. 2017:8(6):777-84.

86. Parker TH, Forstmeier W, Koricheva J, Fidler F, Hadfield JD, Chee YE, Kelly CD, Gurevitch J, Nakagawa S. Transparency in ecology and evolution: real problems, real solutions. TREE. 2016;31(9):711-9.

87. Schmidt NM, Reneerkens J, Christensen JH, Olesen M, Roslin T. An ecosystem-wide reproductive failure with more snow in the Arctic. Plos Biol. 2019;17(10):e3000392.

88. Descamps S, Aars J, Fuglei E, Kovacs KM, Lydersen C, Pavlova O, Pedersen Å, Ravolainen V, Strøm H. Climate change impacts on wildlife in a High Arctic archipelago-Svalbard. Norway Glob Ch Biol. 2017;23(2):490-502.

89. Cooper EJ. Warmer shorter winters disrupt Arctic terrestrial ecosystems. Ann Rev Ecol Evol Syst. 2014;45:271-95.

90. Lembrechts J, van den Hoogen J, Aalto J, Ashcroft M, De Frenne P Kemppinen J, ... Lenoir J. Mismatches between soil and air temperature. EcoEvoRxiv Preprints; 2021.

91. Jarvis A, Reuter HI, Nelson A, Guevara E. Hole-filled seamless SRTM data V4. In: International centre for tropical agriculture (CIAT); 2008. https:// srtm.csi.cgiar.org. Accessed 10 Mar 2021.

92. Walker DA, Raynolds MK, Daniels FJA, Einarsson E, Elvebakk A, Gould WA, Katenin AE, Kholod SS, Markon CJ, Melnikov ES, Moskalenko NG, Talbot SS, Yurtsev BA, Team C. The circumpolar Arctic vegetation map. J Veg Sci. 2005;16:267-82

93. Fick SE, Hijmans RJ. WorldClim 2: new 1-km spatial resolution climate surfaces for global land areas. Int J Clim. 2017;37(12):4302.

94. Park T, Ganguly S, Tømmervik H, Euskirchen ES, Høgda K-A, Karlsen SR, Brovkin V, Nemani RR, Myneni RB. Changes in growing season duration and productivity of northern vegetation inferred from long-term remote sensing data. Environ Res Lett. 2016;11(8):084001.

95. GISTEMP Team, GISS Surface Temperature Analysis (GISTEMP). NASA Goddard Institute for Space Studies; 2016.

96. Hansen J, Ruedy R, Sato M, Lo K. Global surface temperature change. Rev Geophys. 2010. https://doi.org/10.1029/2010RG000345.

97. Haddaway N, Macura B, Whaley P, Pullin A. ROSES flow diagram for systematic maps. Version 1.0; 2017. https://doi.org/10.6084/m9.figshare. 6085940

\section{Publisher's Note}

Springer Nature remains neutral with regard to jurisdictional claims in published maps and institutional affiliations.

Ready to submit your research? Choose BMC and benefit from:

- fast, convenient online submission

- thorough peer review by experienced researchers in your field

- rapid publication on acceptance

- support for research data, including large and complex data types

- gold Open Access which fosters wider collaboration and increased citations

- maximum visibility for your research: over $100 \mathrm{M}$ website views per year

At BMC, research is always in progress.

Learn more biomedcentral.com/submissions 